\title{
Design of Multicomponent Alloys with Single C14 Laves Phase for Hydrogen Storage assisted by Computational Thermodynamic
}

Jéssica Bruna Ponsoni ${ }^{1}$, Vinícius Aranda ${ }^{1}$, Tatiane da Silva Nascimento ${ }^{2}$, Renato Belli Strozi ${ }^{2}$, Walter José Botta ${ }^{1,2}$, Guilherme Zepon ${ }^{1,2}{ }^{*}$

1. Federal University of Sao Carlos, Graduate Program in Materials Science and Engineering (PPGCEM/UFSCar) - Rodovia Washington Luiz, km 235, São Carlos - São Paulo, Brazil CEP:13565-905

2. Federal University of São Carlos, Department of Materials Engineering (DEMa/UFSCar) - Rodovia Washington Luiz, km 235, São Carlos - São Paulo, Brazil CEP:13565-905.

*Corresponding author: zepon@ufscar.br

\begin{abstract}
Design methods with predictive properties modelling are paramount tools to explore the vast compositional field of multicomponent alloys. The applicability of an alloy as a hydrogen storage media is governed by its pressure-compositiontemperature (PCT) diagram. Therefore, the prediction of PCT diagrams for multicomponent alloys is fundamental to design alloys with optimized properties for hydrogen storage applications. In this work, a strategy to design single C14type Laves phase multicomponent alloys for hydrogen storage assisted by computational thermodynamic is presented. Since electronic and geometrical factors play an important role in the formation and stability of multicomponent Laves phase, valence electron concentration (VEC), atomic radius ratio $\left(r_{A} / r_{B}\right)$, and atomic size mismatch $(\delta)$ are initially considered to screen a high number of compositions and find alloy systems prone to form Laves phase structure. Then, CALPHAD method was employed to find 142 alloys of the $(\mathrm{Ti}, \mathrm{Zr}$ or Nb)$(\mathrm{Cr}, \mathrm{Mn}$, $\mathrm{Fe}, \mathrm{Co}, \mathrm{Ni}, \mathrm{Cu}$, or $\mathrm{Zn})_{2}$ system predicted to crystallize as single $\mathrm{C} 14$ Laves phase structure. In addition, we present a thermodynamic model to calculate PCT diagrams of C14 Laves phase alloys based solely on the alloy's composition. In this work, the entropy and enthalpy of hydrogen solution in the C14 Laves phase were modelled considering that hydrogen solid solution occurs only at the $\mathrm{A}_{2} \mathrm{~B}_{2}-$ type interstitial sites of the $\mathrm{C} 14$ Laves phase structure. Experimental pressurecomposition-isotherm (PCl) diagrams of six $\mathrm{C} 14$ Laves phase alloys were compared against the calculated ones resulting in a good prediction capability.
\end{abstract}


Therefore, the room temperature PCl diagrams of 142 single $\mathrm{C} 14$ Laves phase multicomponent alloys were calculated. The results show that single C14 Laves phase multicomponent alloys within a wide range of equilibrium pressure at room temperature can be obtained, being promising candidates for different hydrogen storage applications, such as room temperature tanks, hybrid tanks and Ni-metal hydrides batteries.

\section{Keywords}

Multicomponent alloys; Hydrogen storage; C14 Laves phase; Computational thermodynamics; Thermodynamic model. 


\section{Introduction}

Hydrogen energy is expected to play an important role in a future sustainable economy as an efficient energy vector for energies produced from renewable and clean sources, such as solar and wind. Hydrogen is strategic for energy storage due to its high energy density, efficient production from water electrolysis and by generating only water as byproduct after conversion. However, the use of hydrogen as an effective and cost-effective energy vector remains challenging due to safety and compactness issues [1, 2]. Metal hydrides (MHs) have been considered as a great alternative for solid-state hydrogen storage, providing reversibility, safety, and high volumetric densities. MHs might enable the use of hydrogen energy in various stationary and mobile applications, such as tanks for solid-state hydrogen storage, heat storage systems, fuel cells, and batteries [3, 4]. Each one of these applications demands a different set of properties and, therefore, different MHs. It is worth noting that the hydrogen storage properties of MHs, such as the storage capacity, operation temperaturepressure, and cycling stability are highly dependent on the MH composition [5]. In this scenario, high entropy alloys (HEA), multi-principal element alloys (MPEA), complex concentrated alloys (CCA) or, more generally, multicomponent alloys have been investigated for hydrogen storage since their endless compositional space allows the tuning of hydrogen storage properties of MHs. Multicomponent alloys for hydrogen storage application can be divided into three main groups: body-centered cubic (BCC), lightweight, and intermetallic multicomponent alloys as discussed by Marques et al. [6].

Laves phase has been identified as the most common intermetallic phase among the intermetallic multicomponent alloy, and several times these alloys were constituted by a single Laves phase structure as reported by F. Stein and A. Leineweber [7]. Furthermore, Laves phases are known to reversibly absorb considerable amounts of hydrogen at moderate conditions of temperature and pressure, with good kinetics and sometimes without any activation treatment [813]. Laves phases are classified according to their crystal structures, namely, C14 (MgZnz-type), C15 (MgCu2-type), and C36 (MgNi2-type) [8]. For hydrogen storage, Laves phases are described as $\mathrm{AB}_{2}$ compounds, being $\mathrm{A}$ strong hydride former elements and $B$ elements with low affinity with hydrogen. The classification 
of A- and B-type elements are based on their binary hydride enthalpy of formation. A-type elements have lower values of enthalpy of hydride formation and B-type elements have higher values of enthalpy of hydride formation $[6,14]$. Most of the Laves phase multicomponent alloys for hydrogen storage reported so far are equiatomic, although non-equiatomic compositions within the same alloy system have been studied since it could improve the hydrogen storage behavior as reported in [10-12].

Electronic and geometrical factors are usually associated with the formation and stability of multicomponent Laves phase [15-17]. The main electronic factor is the valence electron concentration (VEC), whereas geometrical factors include atomic radius ratio between A- and B-type elements $\left(r_{A} / r_{B}\right)$ and atomic size mismatch ( $\left.\delta\right)$. Although these factors alone are not sufficient to explain the formation and stability of the Laves phase, they play an important role in the prediction of the Laves phase formation [17, 18]. The development of effective methods to access the vast field of multicomponent alloys, enabling the design and prediction of phase formation and stability, is paramount for design new alloys for hydrogen storage. Calculation Phase Diagrams (CALPHAD) method has been reported as a powerful and consolidated tool to predict phase formation and stability of multicomponent alloys $[6,9,10]$.

The applicability of a $\mathrm{MH}$ in a specific hydrogen storage device is intrinsically related to its pressure-composition-temperature (PCT) diagram, which determines both the maximum hydrogen storage capacity and pressuretemperature operation condition. However, data collection of PCT diagrams is very time-consuming and experimental investigation of a large number of compositions within the multicomponent field is unpractical. Thus, computational tools that allows the prediction of the thermodynamic properties of multicomponent alloys-hydrogen systems are extremely helpful to navigate a large compositional field and to boost the discovery of new alloys with optimized properties for any specific application. Recently, Zepon et al. [19] developed a thermodynamic model for calculating the PCT diagram for BCC multicomponent alloys, which yield accurate predictions of PCT diagrams for different alloy compositions.

In this work, we present a comprehensive strategy to design single C14 Laves phase alloys for hydrogen storage applications assisted by computational 
thermodynamic. High throughput calculation of electronic and geometrical parameters was combined with CALPHAD calculations to find a large number of alloys predicted to crystallize as single C14-type Laves phase structure. In addition, the thermodynamic model reported by Zepon et al. [19] was further developed to calculate PCT diagrams of multicomponent C14-type Laves phase alloys. The prediction of phase stability and PCT diagram were compared with experimental data (both from literature and produced in this work) for different alloys.

\section{Design strategy}

\subsection{Prediction of phase stability}

The design strategy to find single C14 Laves phase alloys comprises two steps: i) high throughput calculation of electronic and geometrical factors to screen a large number of alloy compositions prone to form C14 Laves phase; ii) CALPHAD calculations of these alloys and selecting only those predicted to crystallize as single C14 Laves phase structure.

$A B_{2}$-type systems were selected since the Laves phase presents this stoichiometry. The A elements considered in the designing process are $\mathrm{Ti}, \mathrm{Zr}$ and $\mathrm{Nb}$, and the $\mathrm{B}$ elements are $\mathrm{Cr}, \mathrm{Mn}, \mathrm{Fe}, \mathrm{Co}, \mathrm{Ni}, \mathrm{Cu}$, and $\mathrm{Zn}$. The VEC, $r_{A} / r_{B}$, and $\delta$ parameters were calculated and only alloys presenting these parameters within the ideal ranges for $\mathrm{C} 14$ Laves phase formation were considered to continue in the designing process. The VEC of an alloy is calculated by Equation 1 :

$$
V E C=\sum c_{i} V E C_{i}
$$

where $c_{i}$ is the atomic fraction and $V E C_{i}$ is the valence electron concentration of element $i . V E C_{i}$ is determined by considering the outer electron shell of the individual element. The total number of outer shell electrons for the $A$ and $B$ elements in the present study are $\mathrm{Ti}=4\left(3 \mathrm{~d}^{2} 4 \mathrm{~s}^{2}\right), \mathrm{Zr}=4\left(4 \mathrm{~d}^{2} 5 \mathrm{~s}^{2}\right), \mathrm{Nb}=5\left(4 \mathrm{~d}^{4} 5 \mathrm{~s}^{1}\right)$, $\mathrm{Cr}=6\left(3 \mathrm{~d}^{5} 4 \mathrm{~s}^{1}\right), \mathrm{Mn}=7\left(3 \mathrm{~d}^{5} 4 \mathrm{~s}^{2}\right), \mathrm{Fe}=8\left(3 \mathrm{~d}^{6} 4 \mathrm{~s}^{2}\right), \mathrm{Co}=9\left(3 \mathrm{~d}^{7} 4 \mathrm{~s}^{2}\right), \mathrm{Ni}=10\left(3 \mathrm{~d}^{8} 4 \mathrm{~s}^{2}\right)$, and $\mathrm{Zn}=12\left(3 \mathrm{~d}^{10} 4 \mathrm{~s}^{2}\right)$, as summarized in Table 1. $r_{A} / r_{B}$ is calculated by Equation 2: 


$$
\frac{r_{A}}{r_{B}}=\frac{\sum_{i} c_{i}^{A} \cdot r_{i}}{\sum_{i} c_{i}^{B} \cdot r_{i}}
$$

where $c_{i}^{A}$ and $c_{i}^{B}$ are the atomic fraction of element $i$ in the sublattices $\mathrm{A}$ and $\mathrm{B}$, respectively (i.e., $\sum_{i} c_{i}^{A}=\sum_{i} c_{i}^{B}=1$ ) and $r_{i}$ is atomic radius of element $i$. $\delta$ is calculated by Equation 3:

$$
\delta=\sqrt{\sum c_{i}\left(1-\frac{r_{i}}{\bar{r}}\right)^{2}} \times 100
$$

where $c_{i}$ and $r_{i}$ are the atomic fraction $i$ and $\bar{r}=\sum c_{i} r_{i}$ is the mean atomic radius of all elements in the alloy. In this work, we considered the atomic radius of the pure elements reported by Guo et al. [20]. The values of atomic radii of the elements considered in this work are displayed in Table 1. Gorban et al. [15] reported that $\mathrm{C} 14$ Laves phase is typically formed in multicomponent alloys having VEC within the range of 4.4 and 8.1, however, single C14 Laves phase is formed in a range of $6.4-6.7$. Moreover, they also reported that $\mathrm{C} 14$ Laves phase can be formed for $r_{A} / r_{B}$ ranging from 1.04 to 1.68. Yurchenko et al. [16] showed that Laves phase formation is observed when $\delta>5 \%$.

Finally, thermodynamic calculations were performed using CALPHAD method (Thermo-Calc ${ }^{\mathrm{TM}}$ software and TCHEA3 database) to calculate the amount of equilibrium phases versus temperature for the alloy compositions having $\mathrm{VEC}, r_{A} / r_{B}$, and $\delta$ within the predefined range.

Table 1: Atomic radii (metallic bond), VEC, atomic weight and hydrogen heat of hydrogen solution at infinite dilution of the $A$ and $B$ elements.

\begin{tabular}{|c|c|c|c|c|c|}
\hline \multicolumn{2}{|c|}{ Elements } & $\mathbf{r}[\AA][20]$ & $\mathbf{V E C}_{\boldsymbol{i}}$ & $\mathbf{M}[\mathbf{g} / \mathbf{m o l}]$ & $\Delta \boldsymbol{H}_{\boldsymbol{i}}^{\infty}[\mathbf{k J} / \mathbf{m o l} \mathbf{H}][21]$ \\
\hline \multirow{4}{*}{$\mathbf{A}$} & $\mathbf{T i}$ & 1.46 & 4 & 47.867 & -52 \\
\cline { 2 - 6 } & $\mathbf{Z r}$ & 1.60 & 4 & 91.224 & -52 \\
\cline { 2 - 6 } & $\mathbf{N b}$ & 1.47 & 5 & 92.906 & -35 \\
\hline \multirow{4}{*}{$\mathbf{F e}$} & 1.27 & 8 & 55.845 & 29 \\
\cline { 2 - 6 } & $\mathbf{M n}$ & 1.26 & 7 & 54.938 & 1 \\
\cline { 2 - 6 } & $\mathbf{C r}$ & 1.28 & 6 & 51.996 & 28 \\
\cline { 2 - 6 } & $\mathbf{N i}$ & 1.25 & 10 & 58.693 & 10 \\
\cline { 2 - 6 } & $\mathbf{C o}$ & 1.25 & 9 & 58.933 & 21 \\
\cline { 2 - 6 } & $\mathbf{Z n}$ & 1.39 & 12 & 65.382 & 15 \\
\cline { 2 - 6 } & $\mathbf{C u}$ & 1.28 & 11 & 63.546 & 46 \\
\hline
\end{tabular}

For the sake of clarity, alloys compositions presenting equal atomic fractions of the elements in A and B sublattices will be referred to as "equiatomic". 
On the other hand, "non-equiatomic compositions" are defined as those having A and $B$ sublattices with different atomic fractions. Initially, ten general equiatomic systems (from binary to senary) were defined: $\left(A_{1}\right)\left(B_{1}\right)_{2},\left(A_{1} A_{2}\right)\left(B_{1}\right)_{2},\left(A_{1}\right)\left(B_{1} B_{2}\right)_{2}$, $\left(A_{1} A_{2}\right)\left(B_{1} B_{2}\right)_{2}, \quad\left(A_{1} A_{2} A_{3}\right)\left(B_{1}\right)_{2}, \quad\left(A_{1}\right)\left(B_{1} B_{2} B_{3}\right)_{2}, \quad\left(A_{1} A_{2}\right)\left(B_{1} B_{2} B_{3}\right)_{2}, \quad\left(A_{1} A_{2} A_{3}\right)\left(B_{1} B_{2}\right)_{2}$, $\left(A_{1} A_{2} A_{3}\right)\left(B_{1} B_{2} B_{3}\right)_{2}$ and $\left(A_{1} A_{2}\right)\left(B_{1} B_{2} B_{3} B_{4}\right)_{2}$. Considering all the possible permutations between the $A$ - and B-type elements given in Table 1, we find 546 different alloy compositions that were evaluated by their $\mathrm{VEC}, r_{A} / r_{B}$, and $\delta$ values. The $r_{A} / r_{B}$ values vary in the range from 1.05 to 1.28 for the 546 compositions. These values satisfied the geometrical factor required $(1.04-1.68)$ to obtain single C14-type Laves phase. The $\delta$ values for most of the alloys also satisfied the geometrical factor required $(>5 \%)$ for the formation of the C14 Laves phase. Thereby, since the geometric factors $r_{A} / r_{B}$ and $\delta$ were favorable for most of the alloys, the electronic factor VEC became significant. Among the 546 equiatomic compositions, 162 compositions present VEC in the range of 5.3 to 7.0 , which were considered to have high tendency to form single C14 Laves phase, and 384 compositions have VEC ranging from 7.1 to 9.5 , which were considered as having low tendency to form single C14 Laves phase. All the 162 compositions within VEC ranging from 5.3 to 7.0 had the phase stability investigated by CALPHAD calculation. From the 384 compositions with VEC ranging from 7.1 to $9.5,58$ compositions were randomly selected and calculated by CALPHAD. Therefore, 220 equiatomic compositions were analyzed by CALPHAD calculation and classified into three classes according to the stable phases presented at high temperatures: i) single C14 Laves phase alloys; ii) multi-phase alloys; and iii) single $\mathrm{C} 15$ Laves phase alloys. It is worth mentioning that recent works reported that alloys with a relatively large $\left(>200^{\circ} \mathrm{C}\right)$ single $\mathrm{C} 14$ Laves phase field below solidus temperature (calculated by CALPHAD) presented single phase structure at room temperature for arc-melted samples as, for example, the TiZrCrMnFeNi and $\mathrm{Ti}_{20} \mathrm{Zr}_{20} \mathrm{Nb}_{5} \mathrm{Fe}_{40} \mathrm{Ni}_{15}$ alloys $[9,10]$. Among the multi-phase equiatomic compositions, some of them presented a fraction of $\mathrm{C} 14$ Laves phase. The compositions related to these fractions were non-equiatomic $\mathrm{AB}_{2}$ compositions and were investigated by CALPHAD resulting in new single C14 Laves phase alloys. 100 non-equiatomic single C14 Laves phase were identified. 


\subsection{Thermodynamic model for PCT diagrams calculation}

The thermodynamic model to calculate PCT diagrams for single $\mathrm{C} 14$ Laves phase in this study was based on the model reported by Zepon et al. [19], who proposed a thermodynamic model for BCC multicomponent alloy systems under para-equilibrium (PE) conditions. $\mathrm{PE}$ is a type of thermodynamic equilibrium observed in most of the hydrogen storage applications, which occurs at low or moderate temperatures. In this condition, the mobility of the metals atoms is limited, and it can be assumed that the metal atoms are "frozen" while only the hydrogen atoms are mobile. In this situation, an equilibrium condition is attained because the hydrogen mobility allows the chemical potential of hydrogen to be the same in all the co-existing phases, resulting in the minimum free energy of the system. In contrast, the complete equilibrium (CE) condition is achieved when all atoms of the system have sufficient mobility, usually at high temperatures, so the chemical compositions of the phase can be adjusted to minimize the Gibbs free energy of the system. For a more detailed description regarding thermodynamic of systems under the different degrees of equilibrium that can be observed in $\mathrm{M}-\mathrm{H}$ systems, consider the works reported by $\mathrm{T}$. B. Flanagan and W. A. Oates [22, 23]. Thus, the present work proposes a first thermodynamic model for estimating the enthalpy and entropy of hydrogen solution in the C14 Laves phase alloys under PE, applying the necessary considerations regarding the $\mathrm{C} 14$ Laves phase structure and available interstitial sites for hydrogen absorption.

The crystal structure of the $A B_{2} C 14$ Laves phase is a hexagonal structure with space group $\mathrm{P} 63 / \mathrm{mmc}$ (space group number 194) as illustrated in Figure 1. The structure contains twelve atoms and four formula units per unit cell. The $A$ and $B$ atomic positions are described in Table 2. Figure 2 shows the $A$ and $B$ sublattices that forms the $\mathrm{C} 14$ structure. The $A$ sublattice defines a hexagonal diamond net, while the $\mathrm{B}$ sublattice is composed of $\mathrm{B}_{4}$ tetrahedra alternatively sharing vertices and faces along the $c$ axis as illustrated by Merlino et al. in their study about $\mathrm{Zr}\left(\mathrm{Cr}_{0.5} \mathrm{Ni}_{0.5}\right)_{2}$ Laves phase [24]. These two sublattices merge by vertex sharing in the ab plane to form the $\mathrm{C} 14$ Laves phase structure. Therefore, the $A$ positions are situated in the interstitial sites of the $B$ sublattice. There are three types of tetrahedral interstitial sites in the C14-type Laves phase: $A_{2} B_{2}, A B_{3}$ 
and $B_{4}$, as illustrate in Figure $3(a)$. The $C 14$ structure has 12 equivalent $A_{2} B_{2}$ sites, 4 equivalent $A B_{3}$ sites, and $1 B_{4}$ site per formula unit [24].

In this work, it will be considered the A-type elements ( $\mathrm{Ti}, \mathrm{Zr}$, and $\mathrm{Nb}$ ) will occupy the A positions, and the B-type elements ( $\mathrm{Cr}, \mathrm{Mn}, \mathrm{Fe}, \mathrm{Co}, \mathrm{Ni}, \mathrm{Cu}$, and $\mathrm{Zn}$ ) will occupy the B positions. In other words, there will be solid solution formation of the A-type elements at the A sites and B-type elements at the B sites. It is worth noting that depending on the alloy composition (especially non-equiatomic alloys) A-type elements can partially occupy $B$ sites and vice-versa.

In this work, it will also be considered that the C14 phase will absorb hydrogen only by solid solution, meaning that no equilibrium between two solid phases (a diluted $\mathrm{H}$ solid solution and a high concentration hydride, for example) will be considered. This condition results in an important characteristic of the PCT diagram, which is the absence of a well-defined plateau pressure. This behavior was reported for $\mathrm{Ti}_{20} \mathrm{Zr}_{20} \mathrm{Nb}_{5} \mathrm{Fe}_{40} \mathrm{Ni}_{15}$ [10], $\mathrm{Ti}_{0.5} \mathrm{Zr}_{0.5} \mathrm{~V}_{0.5} \mathrm{Ni}_{1.1} \mathrm{Mn}_{0.2} \mathrm{Fe}_{0.2}$ [11], and $\mathrm{Cr}_{\mathrm{u}} \mathrm{Fe}_{\mathrm{v}} \mathrm{Mn}_{\mathrm{w}} \mathrm{Ti}_{\mathrm{x}} \mathrm{V}_{\mathrm{y}} \mathrm{Zr} \mathrm{r}_{\mathrm{z}}$ [13] alloys with the predominant presence of $\mathrm{C} 14$ Laves phase. As a first approximation, this model will consider that hydrogen atoms will form an interstitial solid solution only in the $A_{2} B_{2}$ interstitial sites. The $A_{2} B_{2}$ sites are preferentially occupied since their absolute value of the binding energy is substantially larger and consequently more energetically stable than $A_{3}$ and $B_{4}$ sites. Moreover, their occupancy preference is related to the trend for hydrogen to fill the tetrahedron constituted by two $\mathrm{A}$ atoms with a high hydrogen affinity as shown by Merlino et al. [24] and Gesari et al. [14] using density functional theory (DFT) calculations. 


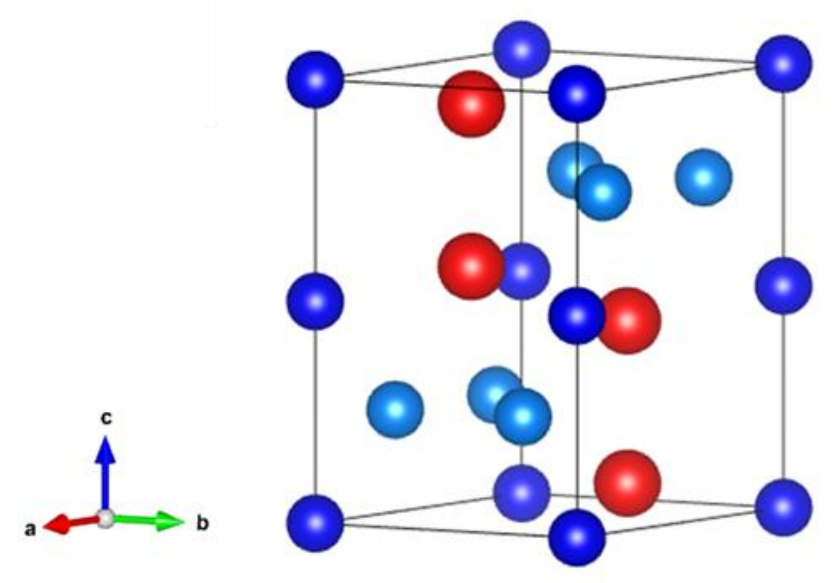

Figure 1: Unit cell of the hexagonal C14 Laves phase (MgZn2-type). The red spheres represent the $A$ positions, and the blue spheres represent the $B$ positions (B positions are divided in two different crystallographic positions: $B 1=$ dark blue and B2 = light blue).

(a)

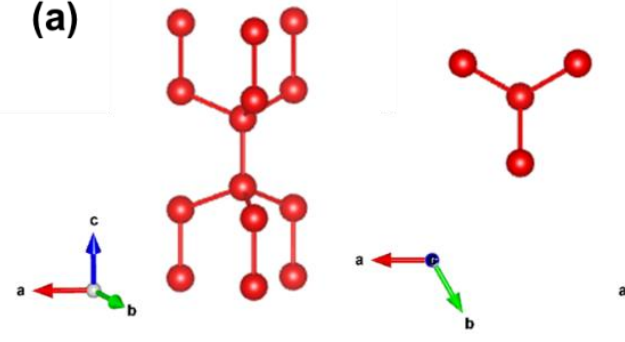

(b)

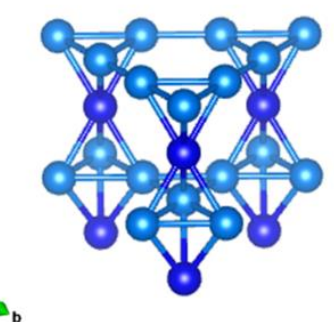

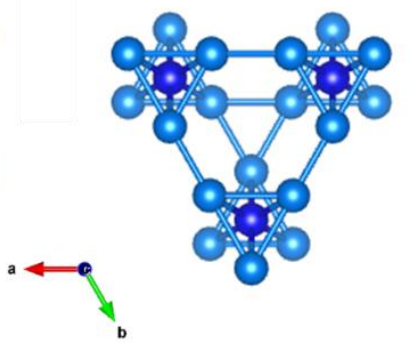

Figure 2: $A$ and $B$ sublattices form the $C 14$ Laves phase. (a) A sublattice and (b) $B$ sublattice projected along to the $c$ direction and top view.

Table 2: Atomic positions of the $A$ and $B$ elements.

\begin{tabular}{|c|c|c|c|c|c|c|}
\cline { 3 - 7 } \multicolumn{2}{c|}{} & \multicolumn{5}{c|}{ Atomic positions } \\
\hline Element & Label & $\mathbf{x}$ & $\mathbf{y}$ & $\mathbf{z}$ & $\begin{array}{c}\text { Wyckoff } \\
\text { Site }\end{array}$ & Occupancy factor \\
\hline $\mathrm{A}$ & $\mathrm{A} 1$ & $1 / 3$ & $2 / 3$ & 0.064 & $4 \mathrm{f}$ & 1 \\
\hline $\mathrm{B}$ & $\mathrm{B} 1$ & 0 & 0 & 0 & $2 \mathrm{a}$ & 1 \\
\hline $\mathrm{B}$ & $\mathrm{B} 2$ & 0.835 & 0.67 & $1 / 4$ & $6 \mathrm{~h}$ & 1 \\
\hline
\end{tabular}



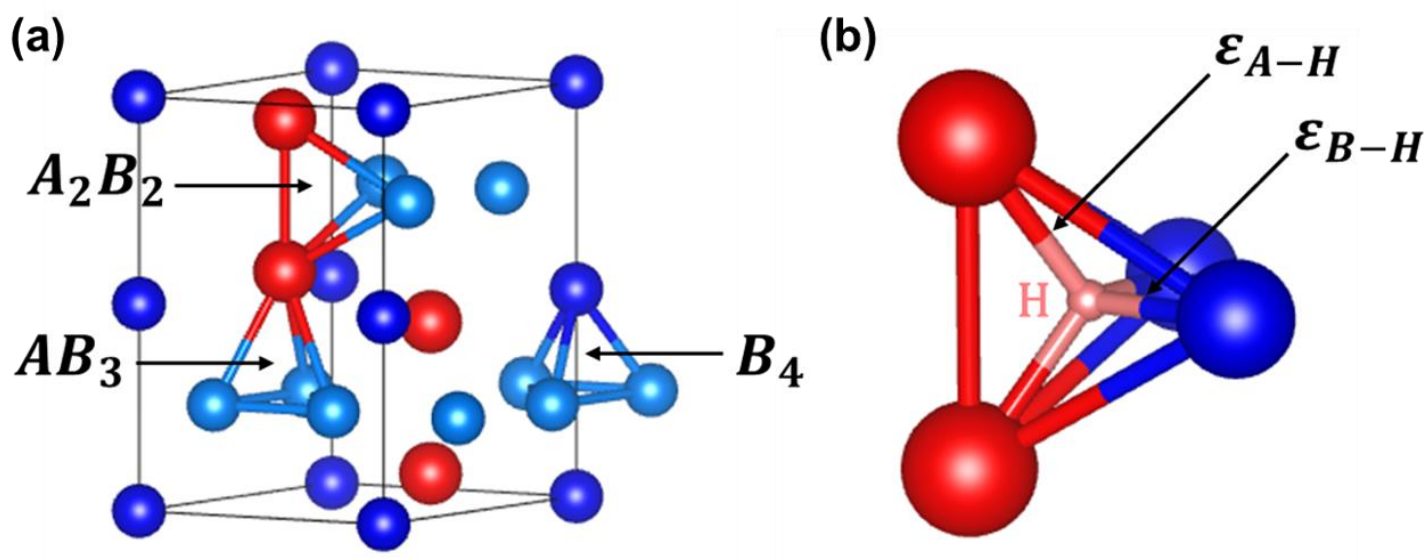

Figure 3: (a) Unit cell of the hexagonal C14 Laves phase (MgZn three types of tetrahedral interstices available: $A_{2} B_{2}, A_{3}$ and $B_{4}$. (b) $A_{2} B_{2}$ sites formed by a tetrahedron having 2 bonds with energy $\varepsilon_{A-H}$ and 2 bonds with energy $\varepsilon B-H$.

For thermodynamic studies of metal-hydrogen $(\mathrm{M}-\mathrm{H})$ systems, the reference state is usually $\mathrm{H}_{2}$ gas at $1 \mathrm{~atm}$ and $\mathrm{M}$ in its stable form. In this study, the chosen reference state will be the $\mathrm{C} 14$ Laves phase alloy without hydrogen and $\mathrm{H}_{2}$ at $1 \mathrm{~atm}$. The amount of hydrogen in the phase is determined as:

$$
c_{H}=\frac{n_{H}}{n_{M}}
$$

where $n_{H}$ and $n_{M}$ are the number of mols of hydrogen and metal atoms in the phase, respectively. Therefore, the entropy of hydrogen mixing $\left(\Delta S_{m}\right)$ is defined by Equation 5 .

$$
\Delta S_{m}\left(C_{H}\right)=S\left(M H_{C_{H}}^{C 14}\right)-S\left(M^{C 14}\right)-\frac{c_{H}}{2} S^{0}\left(H_{2}\right)
$$

where $S\left(M H_{C_{H}}^{C 14}\right)$ and $S\left(M^{C 14}\right)$ are the entropy of the $C 14$ Laves phase with hydrogen content equal to $c_{H}$ and without hydrogen $\left(c_{H}=0\right)$, respectively, and $S^{\circ}\left(H_{2}\right)$ is the standard entropy of $\mathrm{H}_{2}$ gas $\left(P_{H_{2}}=1 \mathrm{~atm}\right)$ which is given by Equation $6[25]$.

$$
S^{0}\left(H_{2}\right)=\frac{7}{2}+\ln \left(\frac{T}{T^{*}}\right)^{\frac{7}{2}}
$$

where $T^{*}=9.2 \mathrm{~K}$. The entropy of a phase can be determined as a sum of the configurational and non-configurational entropy contribution. In this work, we will 
assume that the difference between the non-configurational entropy terms of $M H_{C_{H}}^{C 14}$ and $M^{C 14}$ is negligible. Therefore, Equation 5 becomes Equation 7.

$$
\Delta S_{m}\left(C_{H}\right)=S_{c}\left(M H_{C_{H}}^{C 14}\right)-S_{c}\left(M^{C 14}\right)-\frac{C_{H}}{2} S^{0}\left(H_{2}\right)(7)
$$

where $S_{c}\left(M H_{C_{H}}^{C 14}\right)$ and $S_{c}\left(M^{C 14}\right)$ are the configurational entropy of the C14 Laves phase with hydrogen content equal to $c_{H}$ and without hydrogen $\left(c_{H}=0\right)$. $S_{C}\left(M^{C 14}\right)$ is the entropy of the alloy in its reference state, which will be considered as a sum of the contribution of the ideal configurational entropy of the sublattice A and sublattice B weighted by their atomic fractions as given by Equation 8 .

$$
S_{c}\left(M^{C 14}\right)=-R\left(\frac{1}{3} \sum_{i} c_{i}^{A} \ln c_{i}^{A}+\frac{2}{3} \sum_{i} c_{i}^{B} \ln c_{i}^{B}\right)
$$

where $\mathrm{R}$ is the ideal gas constant, $c_{i}^{A}$ is the atomic fraction of element $i$ in the sublattice $\mathrm{A}$, and $c_{i}^{B}$ is the atomic fraction of element $i$ in the sublattice $\mathrm{B}$ (therefore, $\sum c_{i}^{A}=\sum c_{i}^{B}=1$ ).

$S_{c}\left(M H_{c_{H}}^{C 14}\right)$ is described as the sum of the configurational entropy of the substitutional solid solution of the metal lattice and the configurational entropy of interstitial solid solution of hydrogen in the interstitial sites as given in Equation 9.

$$
\begin{gathered}
S_{c}\left(M H_{c_{H}}^{C 14}\right)=-R\left[\frac{1}{3} \sum_{i} c_{i}^{A} \ln c_{i}^{A}+\frac{2}{3} \sum_{i} c_{i}^{B} \ln c_{i}^{B}+c_{H} \ln \left(\frac{c_{H}}{\theta-\left[(r-1) c_{H}\right]}\right)\right. \\
\left.+\left(\theta-r c_{H}\right) \ln \left(\frac{\theta-r c_{H}}{\theta-\left[(r-1) c_{H}\right]}\right)\right]
\end{gathered}
$$

$\theta$ is the number of interstitial sites per atom of metal and $r$ is associated with the number of interstitial sites that are blocked and do not participate in the mixing process as proposed by J. Garcés [26], and considered by Zepon et al. [19]. Since there are 12 interstitial sites $\mathrm{A}_{2} \mathrm{~B}_{2}$ and 12 atoms of metal per unit cell of $\mathrm{C} 14$ Laves phase, $\theta=1$. In this work, no site blocking effect (SBE) will be considered to occur for the $\mathrm{C} 14$ Laves phase, therefore, $r=1$. For more details regarding the configurational entropy expression which considers SBE refers to $[19,26]$. Thereby, by replacing Equations 5, 6 and 7, $\theta=1$, and $r=1$ into $4, \Delta S_{m}\left(C_{H}\right)$ becomes Equation 10.

$$
\Delta S_{m}\left(C_{H}\right)=-R\left[c_{H} \ln c_{H}+\left(1-c_{H}\right) \ln \left(1-c_{H}\right)\right]-\frac{c_{H}}{2} S_{H_{2}}^{\circ}
$$


A second approximation of this model is that the enthalpy of hydrogen mixing $\Delta H_{m}\left(c_{H}\right)$ in the $\mathrm{C} 14$ Laves phase varies linearly with the hydrogen concentration, as described by Equation 11 .

$$
\Delta H_{m}\left(c_{H}\right)=H_{C 14}+h_{C 14} c_{H}
$$

$H_{C 14}$ is a constant and $h_{C 14}$ is the hydrogen partial molar enthalpy of the C14 phase. Since the chosen reference state was chosen as the $\mathrm{C} 14$ Laves phase alloy without hydrogen, i.e., $c_{H}=0$, then $H_{C 14}=0$. For the $C 14$ Laves phase, $h_{C 14}$ will be described as a sum of the contribution of the hydrogen partial molar enthalpy of the pure elements in the sublattice $A$ and sublattice $B$ in the $A_{2} B_{2}$ tetrahedron occupied by the hydrogen, as given by Equation 12 .

$$
h_{C 14}=\frac{1}{2} \sum_{i} c_{i}^{A} \Delta H_{i}^{\infty}+\frac{1}{2} \sum_{i} c_{i}^{B} \Delta H_{i}^{\infty}
$$

In this work, we approximate the contribution of the hydrogen partial molar of an element $i$ by its enthalpy of hydrogen solution at infinite dilution $\left(\Delta H_{i}^{\infty}\right)$. Experimental values of $\Delta H_{i}^{\infty}$ are available in the [21]. Table 1 presents the values of $\Delta H_{i}^{\infty}$ for the $\mathrm{A}$ and $\mathrm{B}$ elements considered in this work.

More details regarding the deduction of the Equation 12 can be obtained through the total bond energy between elements $A$ and $B$ with the hydrogen atom at the interstitial site $A_{2} B_{2}$, as shown in Figure $3(b)$. This model assumes that the binding energy of element $i$ with hydrogen is approximated by $\varepsilon_{i-H}=\frac{\Delta H_{i}^{\infty}}{4}$ (considering that in a tetrahedron site four metal-hydrogen bonds are formed). Therefore, $h_{C 14}=2 \varepsilon_{A-H}+2 \varepsilon_{B-H}$, where $\varepsilon_{A-H}=\sum c_{i}^{A} \frac{\Delta H_{i}^{\infty}}{4}$ and $\varepsilon_{B-H}=\sum c_{i}^{B} \frac{\Delta H_{i}^{\infty}}{4}$, which yields Equation 12 .

In possession of $\Delta S_{m}\left(c_{H}\right)$ and $\Delta H_{m}\left(c_{H}\right)$, the Gibbs free energy of hydrogen mixing in the $\mathrm{C} 14$ Laves phase can be easily assessed as given by equation 13 :

$$
\Delta G_{m}\left(c_{H}\right)=\Delta H_{m}\left(c_{H}\right)-T \Delta S_{m}\left(c_{H}\right)
$$

where $\Delta G_{m}\left(c_{H}\right)$ describe the change in the Gibbs free energy between the $\mathrm{C} 14$ Laves phase having composition $c_{H}$ and the reference state. It is important to emphasize that the Gibbs free energy of the C14 Laves phase depends only on $c_{H}$ because we are considering para-equilibrium (PE) condition, therefore, the chemical composition of the $\mathrm{C} 14$ Laves phase in terms of metal atoms is maintained constant during hydrogenation. 
The thermodynamic equilibrium of the $\mathrm{M}-\mathrm{H}$ system depends on the hydrogen chemical potential of the possible phases in the system. The hydrogen chemical potential of the C14 Laves phase is given by Equation 14 while the hydrogen chemical potential of $\mathrm{H}_{2}$ gas per mol of hydrogen atom is given by Equation 15.

$$
\begin{gathered}
\mu_{H}^{C 14}\left(c_{H}\right)=\frac{d \Delta G_{m}\left(c_{H}\right)}{d c_{H}} \\
\mu_{H}^{H_{2}}=\frac{1}{2} R T \ln \left(\frac{P_{H_{2}}}{p^{0}}\right)
\end{gathered}
$$

where $p^{0}=1 \mathrm{~atm}$ is the reference state. Therefore, to determine the hydrogen concentration in solid solution in a C14 Laves phase for a given hydrogen pressure and $\left(P_{\mathrm{H}_{2}}\right)$ and a given temperature, both hydrogen chemical potential of the $\mathrm{C} 14$ Laves and the hydrogen chemical potential of $\mathrm{H}_{2}$ gas must be the same, $\mu_{H}^{C 14}=\mu_{H}^{H_{2}}$. From Equations 10, 11, 12 and 13, $\mu_{H}^{C 14}\left(c_{H}\right)$ can be determined analytically. Therefore, Equation 14 becomes Equation 16.

$$
\mu_{H}^{C 14}\left(c_{H}\right)=h_{C 14}-T\left[-R \ln \left(\frac{c_{H}}{1-c_{H}}\right)-\frac{S_{H_{2}}^{\circ}}{2}\right]
$$

Thereby, having $\mu_{H}^{C 14}\left(c_{H}\right)$ and $\mu_{H}^{H_{2}}$, pressure-composition-isotherm curves can be calculated using Equation 17.

$$
\ln \left(\frac{P_{H_{2}}}{p^{0}}\right)=\frac{2}{R T}\left(h_{C 14}-T\left[-R \ln \left(\frac{c_{H}}{1-c_{H}}\right)-\frac{S_{H_{2}}^{\circ}}{2}\right]\right)
$$

\section{Experimental procedures}

\subsection{Sample production and structural characterization.}

To verify the prediction capability of the design method proposed, two equiatomic alloy compositions (one ternary and other quinary) predicted to form single $\mathrm{C} 14$ Laves phase structure, namely $(\mathrm{TiNb})_{1} \mathrm{Fe}_{2}$ and $(\mathrm{TiNb})_{1}(\mathrm{FeMnCr})_{2}$, were produced by arc-melting under an inert argon atmosphere from pure elements (purity $>99 \%$ ). Titanium getters were melted previous to the alloys to reduce the oxygen content in the melting chamber. To ensure chemical homogeneity, the samples were turned over and re-melted at least three times. The structural characterization was conducted via X-ray Diffraction (XRD) using 
a Bruker D8 Advance Eco diffractometer with KaCu radiation. The XRD profiles were analyzed by Rietveld refinement method using the GSAS-II software to determine lattice parameters and phase fraction. The chemical composition of the as-cast alloys was determined by Energy Dispersive Spectroscopy (EDX) using a Bruker Nano XFlash 6|60 EDX Detector in a Philips XL-30 FEG Scanning Electron Microscope (SEM). For the XRD and EDX analysis, the as-cast ingot samples were crushed into powder inside an argon filled MBRAUM glovebox $\left(\mathrm{H}_{2} \mathrm{O}\right.$ and $\mathrm{O}_{2}$ levels below $\left.0.1 \mathrm{ppm}\right)$ using an agate mortar and pestle.

\subsection{PCl measurements}

Experimental $\mathrm{PCl}$ diagrams at room temperature for the $(\mathrm{TiNb}){ }_{1} \mathrm{Fe}_{2}$ and $(\mathrm{TiNb})_{1}(\mathrm{FeMnCr})_{2}$ were measured. The acquisition of $\mathrm{PCl}$ curves was carried out in a Sieverts-type apparatus (Setaram PCT Pro version E\&E). Before PCl measurements, the ingot samples were crushed inside an argon filled MBRAUM glovebox $\left(\mathrm{H}_{2} \mathrm{O}\right.$ and $\mathrm{O}_{2}$ levels below $\left.0.1 \mathrm{ppm}\right)$ using an agate mortar and pestle. To avoid any deleterious effect and ensure a good first hydrogenation, prior to the $\mathrm{PCl}$ measurement the samples were subjected to an activation procedure at $450{ }^{\circ} \mathrm{C}$ under dynamic vacuum for 3 hours. For each composition, a $\mathrm{PCl}$ measurement at room temperature was conducted by applying variable hydrogen doses up to the maximum pressure of 80 bar (high pressure limit of the equipment).

\section{Results and discussion}

\subsection{Prediction of phase stability}

The phase stability of the 220 selected compositions described in section 2.1 were evaluated by CALPHAD calculation. Figure 4 display the 220 alloys in a $r_{A} / r_{B}$ versus VEC chart indicating the alloy classification as single C14 Laves phase; multi-phase; or single C15 Laves phase alloys. The 162 equiatomic compositions selected as prone to form single C14 Laves phase, based on VEC, $r_{A} / r_{B}$, and $\delta$ values, are represented by circles. Among the 162 equiatomic alloys, only 42 compositions were predicted to form single $\mathrm{C} 14$ Laves phase structure 
by CALPHAD calculation and are represented by blue circles. The compositions that were predicted to form multi-phase alloys are represented by red circles and the compositions predicted to form single C15 Laves phase are represented by green circles. Furthermore, the calculations of the 58 compositions randomly selected within VEC range of $7.1-9.5$ are represented by squares. All these compositions resulted in multi-phase or single C15 Laves phase. Among the multi-phase compositions within the entire VEC range, 100 non-equiatomic compositions presented C14 Laves phase as one of the predicted phases. These compositions were considered as new non-equiatomic alloys (represented by triangles) and their phase stability was evaluated by CALPHAD calculation. The 100 non-equiatomic alloys presented a large single C14 phase field at high temperature. Therefore, through the CALPHAD calculations we found 142 compositions predicted to form single $\mathrm{C} 14$ Laves phase structure.

Table 3 shows the 142 single C14 Laves phase compositions numbered from 1 to 42 for equiatomic compositions and from 43 to 142 for non-equiatomic compositions. The chemical composition is given in atomic fraction and the values of VEC, $r_{A} / r_{B}$, and $\delta$ are also given in Table 3 . The range of values with the highest incidence of single $\mathrm{C} 14$ Laves phase compositions is $6.0 \leq \mathrm{VEC} \leq 7.0$ and $1.150 \leq r_{A} / r_{B} \leq 1.223$. 


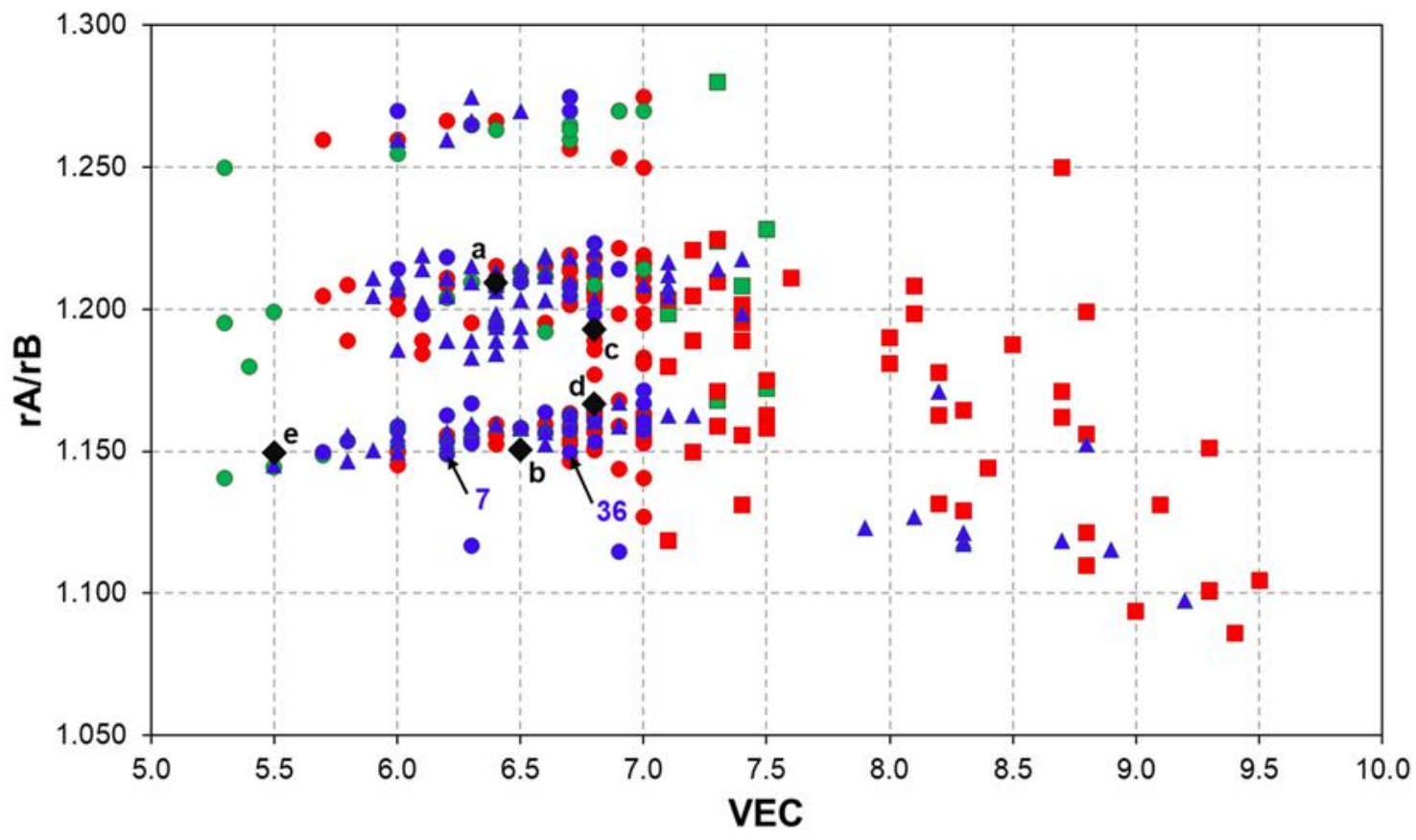

O Tendency to form C14 Laves phase (equiatomic) $\square$ Tendency to not form C14 Laves phase (equiatomic) $\Delta$ Non-equiatomic compositions

$\square$ Single C14 Laves phase $\square$ Single C15 Laves phase $\square$ Multi-phase Experimental (literature)

Figure 4: Results of the thermodynamic calculations by CALPHAD method from 220 equiatomic compositions and 100 non-equiatomic compositions represented in a $r_{A} / r_{B}$ versus VEC chart. The single C14 Laves phase compositions $(\mathrm{TiNb})_{1} \mathrm{Fe}_{2}$ and $(\mathrm{TiNb})_{1}(\mathrm{FeMnCr})_{2}$ that was experimentally produced in this work are indicated by arrows (alloy number 7 and 36, respectively). The experimental compositions reported in the literature as single C14 Laves phase alloys are represented as black diamonds: (a) $(\mathrm{TiZr})_{1}(\mathrm{CrMnFeNi})_{2}$ [9] (b) $\left(\mathrm{Ti}_{13} \mathrm{Zr}_{20}\right)_{1}\left(\mathrm{Nb}_{2.5} \mathrm{Fe}_{20} \mathrm{Ni}_{7.5} \mathrm{Ti}_{3.5}\right)_{2} \quad$ [10] $\quad$ (c) $(\mathrm{TiZr})_{1}\left(\mathrm{~V}_{0.25} \mathrm{Ni}_{0.55} \mathrm{Mn}_{0.1} \mathrm{Fe}_{0.1}\right)_{2} \quad$ [11] $\quad$ (d) $(\mathrm{TiVZr})_{1}(\mathrm{CoFeMn})_{2}$ [27] and (e) $\mathrm{Ti}_{1}\left(\mathrm{Cr}_{0.75} \mathrm{Mn}_{0.25}\right)_{2}[12]$. 
Table 3: Compositions predicted to form single C14 Laves phase by CALPHAD calculations. The alloys were named as number 1 to 42 for equiatomic compositions and 43 to 142 for non-equiatomic compositions. For each composition, the atomic fraction of the elements and their VEC, $\mathrm{r}_{\mathrm{A}} / \mathrm{r}_{\mathrm{B}}$, and $\delta$ parameter are presented.

\begin{tabular}{|c|c|c|c|c|c|c|c|c|c|c|c|c|c|}
\hline \multirow{2}{*}{$\begin{array}{c}\text { Alloy } \\
\text { number }\end{array}$} & \multicolumn{10}{|c|}{ Concentration atomic fraction } & \multirow{2}{*}{$r_{A} / r_{B}$} & \multirow{2}{*}{ VEC } & \multirow{2}{*}{$\delta$} \\
\hline & $\mathrm{Ti}$ & $\mathrm{Zr}$ & $\mathrm{Nb}$ & Fe & Mn & $\mathrm{Cr}$ & $\mathrm{Ni}$ & Co & Zn & $\mathrm{Cu}$ & & & \\
\hline 1 & 0.3333 & & & 0.6667 & & & & & & & 1.150 & 6.7 & 6.7 \\
\hline 2 & 0.3333 & & & & 0.6667 & & & & & & 1.159 & 6.0 & 7.1 \\
\hline 3 & & 0.3333 & & & 0.6667 & & & & & & 1.270 & 6.0 & 11.7 \\
\hline 4 & & & 0.3333 & 0.6667 & & & & & & & 1.157 & 7.0 & 7.1 \\
\hline 5 & & & 0.3333 & & 0.6667 & & & & & & 1.167 & 6.3 & 7.4 \\
\hline 6 & 0.1667 & 0.1667 & & 0.6667 & & & & & & & 1.205 & 6.7 & 9.5 \\
\hline 7 & 0.1667 & & 0.1667 & 0.6667 & & & & & & & 1.154 & 6.8 & 6.9 \\
\hline 8 & & 0.1667 & 0.1667 & & 0.6667 & & & & & & 1.218 & 6.2 & 10.0 \\
\hline 9 & 0.1667 & 0.1667 & & & 0.6667 & & & & & & 1.214 & 6.0 & 9.9 \\
\hline 10 & 0.1667 & & 0.1667 & & 0.6667 & & & & & & 1.163 & 6.2 & 7.3 \\
\hline 11 & 0.3333 & & & 0.3333 & 0.3333 & & & & & & 1.154 & 6.3 & 6.9 \\
\hline 12 & 0.3333 & & & & 0.3333 & 0.3333 & & & & & 1.150 & 5.7 & 6.7 \\
\hline 13 & & 0.3333 & & 0.3333 & 0.3333 & & & & & & 1.265 & 6.3 & 11.5 \\
\hline 14 & & 0.3333 & & & 0.3333 & & & 0.3333 & & & 1.275 & 6.7 & 11.9 \\
\hline 15 & & & 0.3333 & 0.3333 & 0.3333 & & & & & & 1.162 & 6.7 & 7.3 \\
\hline 16 & & & 0.3333 & 0.3333 & & 0.3333 & & & & & 1.153 & 6.3 & 6.9 \\
\hline 17 & & & 0.3333 & & 0.3333 & 0.3333 & & & & & 1.157 & 6.0 & 7.1 \\
\hline 18 & & & 0.3333 & & 0.3333 & & & 0.3333 & & & 1.171 & 7.0 & 7.6 \\
\hline 19 & & & 0.3333 & & & 0.3333 & & 0.3333 & & & 1.157 & 6.7 & 7.3 \\
\hline 20 & & 0.1667 & 0.1667 & & 0.3333 & & & 0.3333 & & & 1.223 & 6.8 & 10.2 \\
\hline 21 & 0.1667 & 0.1667 & & 0.3333 & 0.3333 & & & & & & 1.117 & 6.3 & 9.7 \\
\hline
\end{tabular}




\begin{tabular}{|c|c|c|c|c|c|c|c|c|c|c|c|c|c|}
\hline 22 & 0.1667 & & 0.1667 & 0.3333 & 0.3333 & & & & & & 1.158 & 6.5 & 7.1 \\
\hline 23 & 0.1667 & & 0.1667 & 0.3333 & & 0.3333 & & & & & 1.149 & 6.2 & 6.7 \\
\hline 24 & 0.1667 & & 0.1667 & & 0.3333 & 0.3333 & & & & & 1.154 & 5.8 & 6.9 \\
\hline 25 & 0.1111 & 0.1111 & 0.1111 & & 0.6667 & & & & & & 1.198 & 6.1 & 9.2 \\
\hline 26 & & 0.3333 & & 0.2222 & 0.2222 & & & 0.2222 & & & 1.270 & 6.7 & 11.7 \\
\hline 27 & & & 0.3333 & 0.2222 & 0.2222 & 0.2222 & & & & & 1.157 & 6.3 & 7.1 \\
\hline 28 & & & 0.3333 & & 0.2222 & 0.2222 & & 0.2222 & & & 1.164 & 6.6 & 7.4 \\
\hline 29 & 0.3333 & & & & 0.2222 & 0.2222 & & & 0.2222 & & 1.115 & 6.9 & 6.2 \\
\hline 30 & & & 0.3333 & 0.2222 & 0.2222 & & & 0.2222 & & & 1.167 & 7.0 & 7.5 \\
\hline 31 & & & 0.3333 & 0.2222 & & 0.2222 & 0.2222 & & & & 1.161 & 7.0 & 7.2 \\
\hline 32 & & & 0.3333 & 0.2222 & & 0.2222 & & 0.2222 & & & 1.161 & 6.8 & 7.2 \\
\hline 33 & & & 0.3333 & & 0.2222 & 0.2222 & 0.2222 & & & & 1.164 & 6.8 & 7.4 \\
\hline 34 & 0.1667 & 0.1667 & & 0.2222 & 0.2222 & & & 0.2222 & & & 1.214 & 6.7 & 9.9 \\
\hline 35 & 0.1667 & 0.1667 & & 0.2222 & & 0.2222 & 0.2222 & & & & 1.208 & 6.7 & 9.7 \\
\hline 36 & 0.1667 & & 0.1667 & 0.2222 & 0.2222 & 0.2222 & & & & & 1.154 & 6.2 & 6.9 \\
\hline 37 & 0.1667 & & 0.1667 & 0.2222 & & 0.2222 & & 0.2222 & & & 1.157 & 6.6 & 7.1 \\
\hline 38 & 0.1667 & 0.1667 & & 0.2222 & 0.2222 & & 0.2222 & & & & 1.214 & 6.9 & 9.9 \\
\hline 39 & 0.1667 & 0.1667 & & 0.2222 & 0.2222 & & & 0.2222 & & & 1.163 & 6.7 & 9.9 \\
\hline 40 & 0.1111 & 0.1111 & 0.1111 & 0.3333 & 0.3333 & & & & & & 1.194 & 6.4 & 9.0 \\
\hline 41 & 0.1111 & 0.1111 & 0.1111 & 0.2222 & 0.2222 & & & 0.2222 & & & 1.198 & 6.8 & 9.2 \\
\hline 42 & 0.1667 & 0.1667 & & 0.1667 & 0.1667 & 0.1667 & 0.1667 & & & & 1.209 & 6.5 & 9.7 \\
\hline 43 & 0.0508 & 0.2825 & & & 0.3837 & & & 0.2830 & & & 1.219 & 6.6 & 11.4 \\
\hline 44 & & 0.0399 & 0.2934 & 0.2642 & 0.4024 & & & & & & 1.213 & 6.6 & 8.0 \\
\hline 45 & & 0.3261 & 0.0074 & 0.4201 & 0.2464 & & & & & & 1.213 & 6.4 & 11.4 \\
\hline 46 & 0.2747 & 0.0586 & & & 0.5650 & 0.1013 & 0.0003 & & & & 1.211 & 5.9 & 8.2 \\
\hline 47 & & 0.0050 & 0.3284 & & 0.4387 & 0.1818 & 0.0461 & & & & 1.215 & 6.3 & 7.4 \\
\hline 48 & 0.2342 & 0.1001 & & 0.1800 & 0.4273 & 0.0567 & & & & 0.0016 & 1.202 & 6.1 & 8.8 \\
\hline
\end{tabular}




\begin{tabular}{|c|c|c|c|c|c|c|c|c|c|c|c|c|c|}
\hline 49 & & 0.0056 & 0.3278 & 0.2177 & 0.3289 & 0.1045 & 0.0155 & & & & 1.213 & 6.5 & 7.3 \\
\hline 50 & & 0.0346 & 0.2988 & 0.1359 & 0.3520 & 0.0787 & & 0.1001 & & & 1.213 & 6.6 & 8.0 \\
\hline 51 & 0.3333 & & & 0.5373 & & & 0.1294 & & & & 1.159 & 6.9 & 6.9 \\
\hline 52 & 0.1147 & & 0.2186 & 0.5712 & & & 0.0954 & & & & 1.163 & 7.1 & 7.1 \\
\hline 53 & 0.3333 & & & 0.3854 & 0.1283 & & & 0.1529 & & & 1.159 & 6.7 & 7.0 \\
\hline 54 & 0.0423 & 0.2911 & & 0.3176 & 0.3489 & & & & & & 1.209 & 6.3 & 11.1 \\
\hline 55 & 0.3333 & & & 0.1393 & 0.1027 & & & & 0.4246 & & 1.117 & 8.3 & 5.3 \\
\hline 56 & 0.0897 & 0.2339 & & & 0.6664 & & 0.0099 & & & & 1.219 & 6.1 & 10.7 \\
\hline 57 & 0.0251 & & 0.3083 & & 0.3315 & 0.3351 & & & & & 1.154 & 6.0 & 7.1 \\
\hline 58 & 0.3333 & & 0.0002 & & 0.0936 & 0.0892 & & & 0.4837 & & 1.118 & 8.3 & 4.7 \\
\hline 59 & & 0.0410 & 0.2925 & 0.1611 & 0.4271 & 0.0783 & & & & & 1.209 & 6.4 & 8.0 \\
\hline 60 & 0.1568 & 0.0258 & 0.1509 & 0.2364 & 0.3239 & 0.1064 & & & & & 1.189 & 6.3 & 7.5 \\
\hline 61 & 0.1555 & 0.1778 & & 0.2569 & & & 0.3649 & 0.0449 & & & 1.218 & 7.4 & 10.1 \\
\hline 62 & 0.1175 & 0.2158 & & 0.2349 & 0.3375 & 0.0209 & & 0.0734 & & & 1.209 & 6.4 & 10.4 \\
\hline 63 & 0.1555 & 0.1781 & & 0.3387 & 0.2206 & & 0.1071 & & & 0.0001 & 1.209 & 6.7 & 9.9 \\
\hline 64 & 0.1498 & 0.1835 & & 0.3058 & & 0.0414 & 0.2352 & 0.0842 & & & 1.212 & 7.1 & 10.1 \\
\hline 65 & 0.1345 & & 0.1989 & 0.2567 & 0.2109 & 0.1880 & 0.0111 & & & & 1.158 & 6.3 & 7.0 \\
\hline 66 & 0.0845 & & 0.2488 & 0.2015 & 0.1670 & 0.1953 & & 0.1029 & & & 1.158 & 6.5 & 7.1 \\
\hline 67 & 0.0123 & & 0.3210 & & 0.1929 & 0.2028 & 0.0257 & 0.2453 & & & 1.163 & 6.7 & 7.4 \\
\hline 68 & 0.0038 & & 0.3306 & & 0.6542 & & 0.0113 & & & 0.0001 & 1.160 & 6.4 & 7.5 \\
\hline 69 & 0.0196 & & 0.3137 & & & 0.3449 & 0.0161 & 0.3056 & & 0.0001 & 1.158 & 6.6 & 7.3 \\
\hline 70 & & 0.0170 & 0.3164 & 0.1819 & 0.3389 & & 0.0285 & 0.1174 & & & 1.221 & 6.8 & 7.8 \\
\hline 71 & & 0.0006 & 0.3330 & 0.2726 & & 0.1982 & 0.0239 & 0.1717 & & & 1.216 & 6.8 & 7.2 \\
\hline 72 & & 0.0167 & 0.3167 & & 0.3196 & 0.1332 & 0.0195 & 0.1943 & & & 1.218 & 6.6 & 7.8 \\
\hline 73 & 0.3338 & & & 0.1066 & & 0.5596 & & & & & 1.145 & 5.5 & 6.4 \\
\hline 74 & 0.3333 & & & 0.3849 & & & & 0.2818 & & & 1.159 & 6.9 & 7.1 \\
\hline 75 & & 0.3335 & & & 0.6494 & 0.0172 & & & & & 1.260 & 6.0 & 11.7 \\
\hline
\end{tabular}




\begin{tabular}{|c|c|c|c|c|c|c|c|c|c|c|c|c|c|}
\hline 76 & & 0.2436 & & & 0.7549 & & 0.0016 & & & & 1.275 & 6.3 & 10.9 \\
\hline 77 & 0.2748 & 0.0586 & & & 0.5632 & 0.1034 & & & & & 1.205 & 5.9 & 8.2 \\
\hline 78 & 0.0559 & & 0.2775 & & 0.3763 & & & 0.2904 & & & 1.167 & 6.9 & 7.6 \\
\hline 79 & 0.1260 & & 0.2074 & & & 0.3573 & & 0.3094 & & & 1.158 & 6.5 & 7.1 \\
\hline 80 & & & 0.0626 & 0.2708 & 0.5640 & 0.1025 & & & & & 1.209 & 7.0 & 3.9 \\
\hline 81 & 0.3337 & & & 0.1668 & 0.2889 & 0.2106 & & & & & 1.150 & 6.0 & 6.8 \\
\hline 82 & 0.3334 & & & 0.4097 & 0.2227 & & 0.0342 & & & & 1.159 & 6.5 & 6.9 \\
\hline 83 & 0.3333 & & & 0.4981 & & 0.0462 & 0.1224 & & & & 1.153 & 6.8 & 6.9 \\
\hline 84 & 0.3333 & & & 0.3485 & & 0.1241 & & 0.1941 & & & 1.153 & 6.6 & 6.9 \\
\hline 85 & 0.3337 & & & & 0.4359 & 0.2303 & 0.0001 & & & & 1.156 & 5.8 & 6.9 \\
\hline 86 & 0.3339 & & & & 0.3627 & 0.2836 & & & & 0.0198 & 1.147 & 5.8 & 6.8 \\
\hline 87 & & 0.3335 & & 0.2083 & 0.4471 & 0.0111 & & & & & 1.260 & 6.2 & 11.5 \\
\hline 88 & & 0.3333 & & 0.3489 & 0.2763 & & 0.0415 & & & & 1.270 & 6.5 & 11.5 \\
\hline 89 & & 0.3335 & & & 0.4790 & 0.0105 & & 0.1771 & & & 1.266 & 6.3 & 11.8 \\
\hline 90 & & 0.3335 & & & 0.6493 & 0.0172 & & & & & 1.260 & 6.0 & 11.7 \\
\hline 91 & & 0.3349 & & & 0.6480 & 0.0171 & & & & & 1.260 & 6.0 & 11.7 \\
\hline 92 & & & 0.3342 & & 0.3290 & 0.3365 & & & & 0.0003 & 1.154 & 6.0 & 7.1 \\
\hline 93 & 0.2502 & 0.0833 & & 0.2639 & 0.3434 & 0.0592 & & & & & 1.205 & 6.2 & 8.5 \\
\hline 94 & 0.0603 & 0.2725 & & & 0.5827 & 0.0226 & & 0.0618 & & & 1.214 & 6.1 & 11.1 \\
\hline 95 & 0.3334 & 0.0001 & & & 0.1981 & 0.0215 & & & 0.4469 & & 1.171 & 8.2 & 5.2 \\
\hline 96 & 0.0342 & 0.2991 & & & 0.6461 & 0.0206 & & & & & 1.209 & 6.0 & 11.3 \\
\hline 97 & 0.1199 & & 0.2134 & 0.4167 & & 0.2060 & 0.0440 & & & & 1.157 & 6.6 & 6.9 \\
\hline 98 & 0.1086 & & 0.2248 & & 0.3970 & 0.2674 & 0.0022 & & & & 1.160 & 6.0 & 7.1 \\
\hline 99 & 0.0429 & & 0.2905 & & 0.2836 & 0.2426 & & 0.1404 & & & 1.160 & 6.3 & 7.2 \\
\hline 100 & 0.0652 & & 0.2685 & & 0.3439 & 0.3222 & & & & 0.0003 & 1.151 & 5.9 & 7.0 \\
\hline 101 & & 0.1172 & 0.2162 & 0.1624 & 0.3299 & & & 0.1742 & & & 1.218 & 6.7 & 9.4 \\
\hline 102 & & 0.0001 & 0.3334 & 0.3785 & & 0.2546 & 0.0334 & & & & 1.212 & 6.6 & 7.0 \\
\hline
\end{tabular}




\begin{tabular}{|c|c|c|c|c|c|c|c|c|c|c|c|c|c|}
\hline 103 & & 0.0598 & 0.2737 & & 0.4050 & 0.0980 & & 0.1635 & & & 1.215 & 6.5 & 8.5 \\
\hline 104 & & 0.0542 & 0.2828 & & 0.5526 & 0.1102 & & & & 0.0001 & 1.205 & 6.2 & 8.3 \\
\hline 105 & 0.1875 & 0.0012 & 0.1446 & 0.4464 & & 0.2203 & & & & & 1.184 & 6.4 & 6.8 \\
\hline 106 & 0.1615 & 0.1717 & 0.0001 & 0.2901 & & & 0.3765 & & & & 1.198 & 7.4 & 10.0 \\
\hline 107 & 0.0092 & & 0.3247 & 0.5372 & & & 0.1290 & & & & 1.163 & 7.2 & 7.2 \\
\hline 108 & 0.0002 & 0.0062 & 0.3258 & & 0.5953 & & 0.0724 & & & & 1.203 & 6.5 & 7.6 \\
\hline 109 & 0.0545 & 0.1289 & 0.1499 & & 0.3519 & & & 0.3148 & & & 1.203 & 6.8 & 9.7 \\
\hline 110 & 0.0563 & 0.0660 & 0.2194 & & 0.6582 & & & & & 0.0001 & 1.189 & 6.2 & 8.6 \\
\hline 111 & 0.3333 & & 0.0028 & & & 0.0173 & & & 0.6465 & & 1.097 & 9.2 & 2.6 \\
\hline 112 & 0.1630 & 0.1705 & & 0.2959 & 0.0319 & & 0.3388 & & & & 1.214 & 7.3 & 10.0 \\
\hline 113 & 0.0170 & 0.0032 & 0.3128 & 0.0889 & 0.5679 & & 0.0102 & & & & 1.198 & 6.4 & 7.4 \\
\hline 114 & 0.0399 & 0.0476 & 0.2459 & 0.2783 & 0.3882 & & & & & & 1.194 & 6.5 & 8.1 \\
\hline 115 & 0.3333 & & 0.0001 & 0.1820 & 0.0678 & & & & 0.4168 & & 1.121 & 8.3 & 5.3 \\
\hline 116 & 0.0616 & 0.0756 & 0.2066 & 0.2551 & 0.4010 & & & & & 0.0001 & 1.189 & 6.4 & 8.6 \\
\hline 117 & 0.0714 & 0.2395 & 0.0369 & 0.3653 & 0.2869 & & & & & & 1.194 & 6.4 & 10.5 \\
\hline 118 & 0.0069 & & 0.3262 & 0.2353 & & 0.4174 & 0.0142 & & & & 1.157 & 6.2 & 6.8 \\
\hline 119 & 0.1636 & 0.1698 & & 0.2270 & & 0.1104 & 0.3292 & & & & 1.208 & 7.1 & 9.9 \\
\hline 120 & 0.3333 & & 0.0005 & 0.0928 & & 0.0131 & & & 0.5603 & & 1.115 & 8.9 & 3.9 \\
\hline 121 & 0.0051 & 0.0002 & 0.3283 & 0.3932 & & 0.2732 & & & & & 1.184 & 6.4 & 6.9 \\
\hline 122 & 0.0375 & 0.0002 & 0.2962 & 0.3385 & & 0.3274 & & & & 0.0002 & 1.183 & 6.3 & 6.8 \\
\hline 123 & 0.0229 & 0.0355 & 0.2749 & & 0.4154 & 0.1400 & & 0.1113 & & & 1.195 & 6.4 & 8.0 \\
\hline 124 & 0.0100 & 0.0360 & 0.2873 & & 0.5296 & 0.1370 & & & & & 1.189 & 6.2 & 8.0 \\
\hline 125 & 0.3333 & & 0.0002 & & 0.0898 & 0.0255 & & & 0.5512 & & 1.118 & 8.7 & 4.2 \\
\hline 126 & 0.0870 & 0.0186 & 0.2288 & & 0.4862 & 0.1791 & & & & 0.0003 & 1.186 & 6.0 & 7.5 \\
\hline 127 & 0.0023 & 0.0200 & 0.3111 & & 0.3076 & & 0.0346 & 0.3245 & & & 1.205 & 7.1 & 8.0 \\
\hline 128 & 0.0093 & 0.0692 & 0.2549 & & 0.4953 & & & 0.1713 & & & 1.203 & 6.6 & 8.7 \\
\hline 129 & 0.0272 & 0.0009 & 0.3057 & & & 0.3859 & & 0.2803 & & 0.0002 & 1.189 & 6.5 & 7.2 \\
\hline
\end{tabular}




\begin{tabular}{|c|c|c|c|c|c|c|c|c|c|c|c|c|c|}
\hline 130 & 0.3333 & & & 0.1167 & 0.1667 & 0.0189 & & & 0.3644 & & 1.123 & 7.9 & 5.7 \\
\hline 131 & 0.0645 & 0.2688 & & 0.2120 & 0.4380 & 0.0166 & & & & & 1.205 & 6.2 & 10.9 \\
\hline 132 & 0.1375 & 0.1958 & & 0.3120 & 0.0614 & & 0.1901 & 0.1032 & & & 1.217 & 7.1 & 10.3 \\
\hline 133 & 0.0317 & 0.3014 & & & 0.5569 & 0.0174 & & 0.0926 & & & 1.211 & 6.2 & 11.4 \\
\hline 134 & 0.1216 & 0.2111 & & & 0.5955 & 0.0349 & & 0.0368 & & 0.0001 & 1.207 & 6.0 & 10.4 \\
\hline 135 & 0.0456 & & 0.2878 & 0.1938 & 0.2274 & 0.2455 & & & & & 1.154 & 6.2 & 7.0 \\
\hline 136 & 0.3333 & & 0.0001 & 0.1296 & 0.0830 & 0.0575 & & & 0.3966 & & 1.127 & 8.1 & 5.4 \\
\hline 137 & 0.0911 & & 0.2425 & 0.2015 & 0.2354 & 0.2291 & & & & 0.0003 & 1.151 & 6.2 & 7.0 \\
\hline 138 & 0.0602 & & 0.2729 & 0.2841 & & 0.1844 & 0.0205 & 0.1778 & & & 1.160 & 6.8 & 7.2 \\
\hline 139 & 0.0779 & & 0.2556 & & 0.3420 & 0.2941 & & 0.0302 & & 0.0002 & 1.156 & 6.0 & 7.1 \\
\hline 140 & & 0.0130 & 0.3203 & 0.2016 & 0.3444 & 0.1206 & & & & & 1.209 & 6.4 & 7.4 \\
\hline 141 & & 0.0374 & 0.3041 & 0.1675 & 0.4112 & 0.0797 & & & & 0.0001 & 1.206 & 6.4 & 8.0 \\
\hline 142 & & 0.0560 & 0.2827 & & 0.3932 & 0.1010 & & 0.1670 & & 0.0001 & 1.211 & 6.5 & 8.5 \\
\hline
\end{tabular}


Figure 5 shows, as example, the amount of equilibrium phase as function of temperature calculated by CALPHAD for the equiatomic (TiNb) ${ }_{1} \mathrm{Fe}_{2}$ and ( $\mathrm{TiNb})_{1}(\mathrm{FeMnCr})_{2}$ compositions (alloys number 7 and 36, respectively, indicated by arrows in Figure 4). The thermodynamic calculation shows that the (TiNb) ${ }_{1} \mathrm{Fe}_{2}$ alloy crystallizes as a single C14 Laves phase (Figure 5 (a)). In this case, the single $\mathrm{C} 14$ Laves phase is stable below $1550{ }^{\circ} \mathrm{C}$, and no other phase is predict to form upon cooling. Figure $5(\mathrm{~b})$ shows that the $(\mathrm{TiNb})_{1}(\mathrm{FeMnCr})_{2}$ crystallizes as a major C14 Laves phase and a diminute fraction of a BCC phase $(<2 \%)$ is predicted to form in the final stages of solidification. The same behavior was reported by Edalati et al. in [9] for the TiZrCrMnFeNi alloy, and such alloys, which were practically single $\mathrm{C} 14$ phase when produced by arc-melting were also classified as single $\mathrm{C} 14$ phase alloys. The $(\mathrm{TiNb})_{1} \mathrm{Fe}_{2}$ and $(\mathrm{TiNb})_{1}(\mathrm{FeMnCr})_{2}$ alloys were therefore taken as examples to validate the phase prediction experimentally.

Figure 6 presents the XRD patterns of the as-cast $(\mathrm{TiNb})_{1} \mathrm{Fe}_{2}$ and $(\mathrm{TiNb})_{1}(\mathrm{FeMnCr})_{2}$ alloys confirming that both of them have a single $\mathrm{C} 14$ Laves phase structure. The lattice parameters for the $(\mathrm{TiNb}){ }_{1} \mathrm{Fe}_{2} \mathrm{C} 14$ Laves phases are $\mathrm{a}=0.482 \mathrm{~nm}$ and $\mathrm{c}=0.786 \mathrm{~nm}$, and for the $(\mathrm{TiNb})_{1}(\mathrm{FeMnCr})_{2}$ are $\mathrm{a}=0.487$ $\mathrm{nm}$ and $\mathrm{c}=0.798 \mathrm{~nm}$. The chemical composition of both alloys measured by EDS presented in Table 4 indicate that the average composition of the (TiNb) ${ }_{1} \mathrm{Fe}_{2}$ alloy is in good agreement with the nominal composition. However, for the ( $\mathrm{TiNb})_{1}(\mathrm{FeMnCr})_{2}$ alloy, the experimental $\mathrm{Mn}$ content is lower than the nominal one, which can be explained by its partial vaporization during melting procedure due to its lower vapor pressure compared to the other alloying elements. CALPHAD calculation of the experimental composition of the $(\mathrm{TiNb})_{1}(\mathrm{FeMnCr})_{2}$ alloy confirmed that this composition should also crystallize as single C14 Laves phase (see Figure S1 of the supplementary material file). 

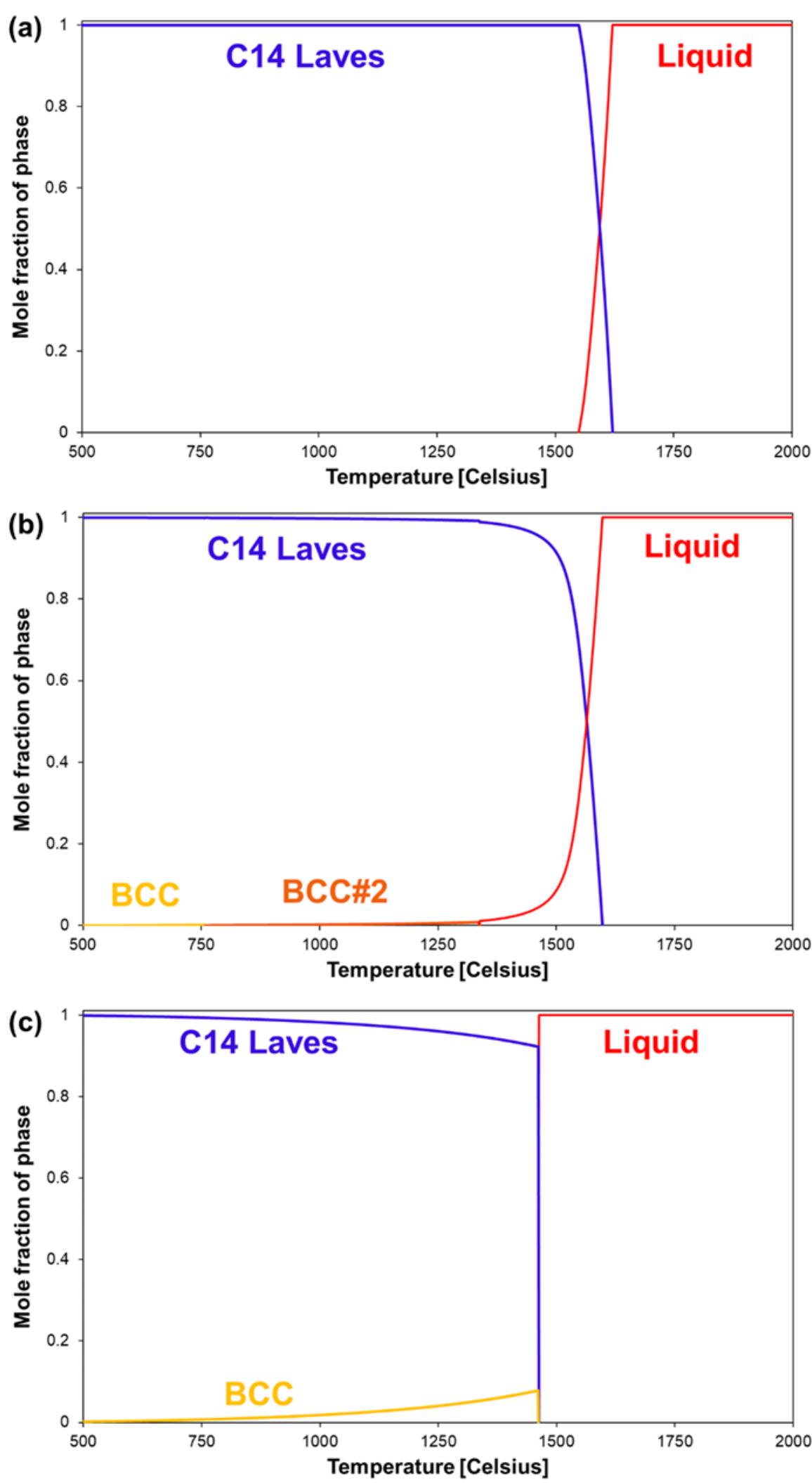

Figure 5: Amount of equilibrium phases as a function of temperature calculated for the (a) (TiNb) ${ }_{1} \mathrm{Fe}_{2}$, (b) (TiNb) ${ }_{1}(\mathrm{FeMnCr})_{2}$ and (c) $\mathrm{Ti}_{1}\left(\mathrm{Cr}_{0.75} \mathrm{Mn}_{0.25}\right)_{2}$ alloys. 

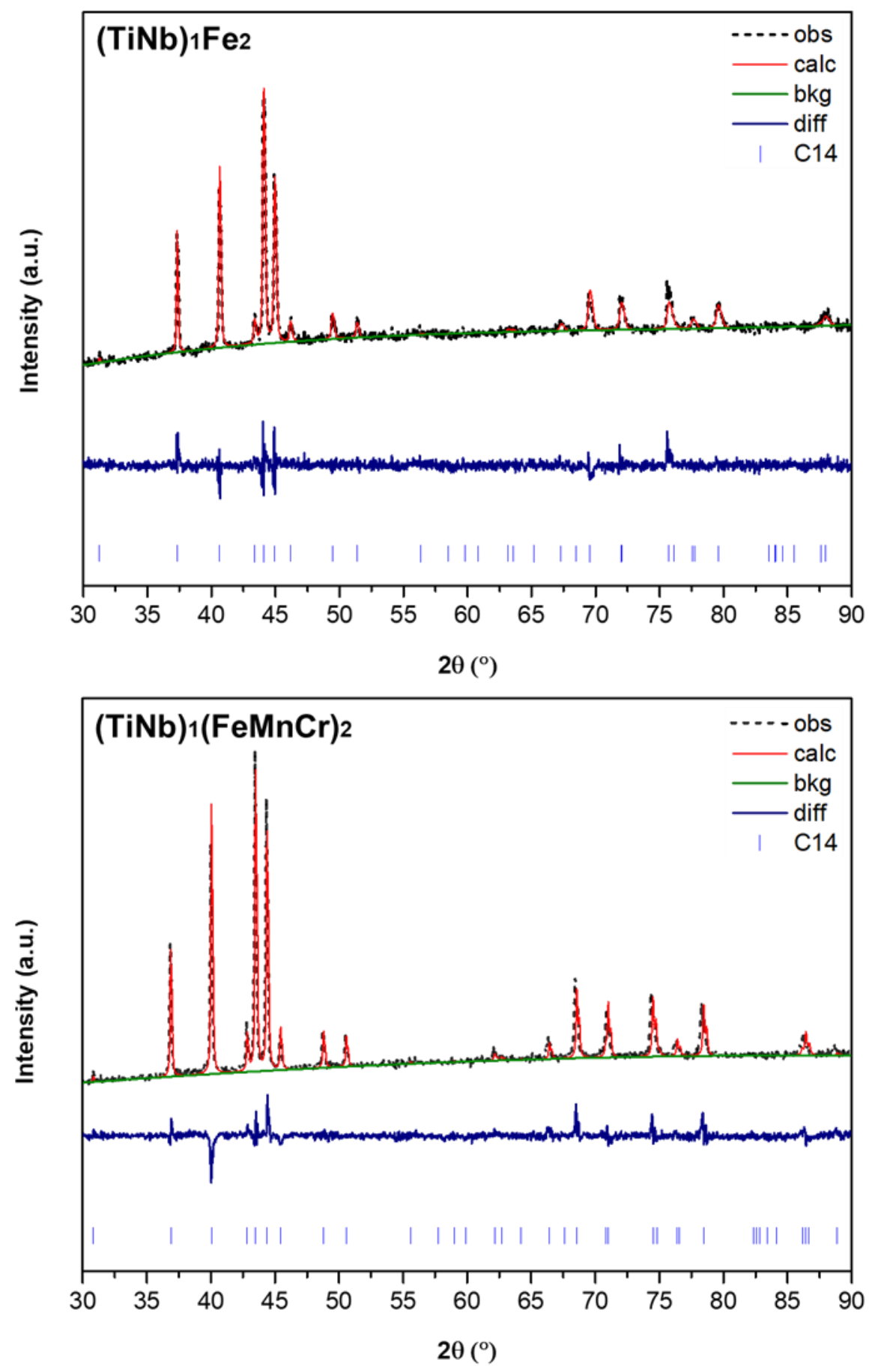

Figure 6: Rietveld refinement of the XRD pattern of the as-cast ( $\mathrm{TiNb})_{1} \mathrm{Fe}_{2}$ and $(\mathrm{TiNb})_{1}(\mathrm{FeMnCr})_{2}$ indicating that both samples formed single $\mathrm{C} 14$ Laves phase structure. No diffraction peaks from a second phase can be seen. 
Table 4: Chemical composition of the $(\mathrm{TiNb})_{1} \mathrm{Fe}_{2}$ and $(\mathrm{TiNb})_{1}(\mathrm{FeMnCr})_{2}$ alloys determined by SEM-EDS from measurement of 10 random regions of the sample.

\begin{tabular}{|c|c|c|c|c|c|}
\cline { 2 - 6 } \multicolumn{1}{c|}{} & \multicolumn{5}{c|}{ Chemical composition in at\% of the as-cast alloys } \\
\hline Alloy & $\mathrm{Ti}$ & $\mathbf{N b}$ & $\mathbf{F e}$ & $\mathbf{M n}$ & $\mathbf{C r}$ \\
\hline \multirow{2}{*}{$(\mathrm{TiNb})_{1} \mathrm{Fe}_{2}$} & 16.4 & 15.5 & 68.1 & & \\
& \pm & \pm & \pm & - & - \\
& 0.5 & 1.3 & 1.5 & & \\
\hline & 18.1 & 15.4 & 24.0 & 18.7 & 23.8 \\
(TiNb) $_{1}(\mathrm{FeMnCr})_{2}$ & \pm & \pm & \pm & \pm & \pm \\
& 1.8 & 1.9 & 0.5 & 1.3 & 1.2 \\
\hline
\end{tabular}

Five alloys reported in the literature that were experimentally demonstrated to be single C14 Laves phase alloys, namely TiZrCrMnFeNi [9], $\mathrm{Ti}_{20} \mathrm{Zr}_{20} \mathrm{Nb}_{5} \mathrm{Fe}_{40} \mathrm{Ni}_{15}$ [10], $\mathrm{Ti}_{0.5} \mathrm{Zr}_{0.5} \mathrm{~V}_{0.5} \mathrm{Ni}_{1.1} \mathrm{Mn}_{0.2} \mathrm{Fe}_{0.2}$ [11], CoFeMnTiVZr [27], and $\mathrm{TiCr}_{1.5} \mathrm{Mnn}_{0.5}$ [12], were added in Figure 4 and are represented as black diamonds. For sake of consistency, the compositions reported in the literature will be described following the $(A)(B)_{2}$ nomenclature adopted in this work, i.e.: $(\mathrm{TiZr})_{1}(\mathrm{CrMnFeNi})_{2} \quad[9], \quad\left(\mathrm{Ti}_{13} \mathrm{Zr}_{20}\right)_{1}\left(\mathrm{Nb}_{2.5} \mathrm{Fe}_{20} \mathrm{Ni}_{7.5} \mathrm{Ti}_{3.5}\right)_{2} \quad$ [10], $(\mathrm{TiZr})_{1}\left(\mathrm{~V}_{0.25} \mathrm{Ni}_{0.55} \mathrm{Mn}_{0.1} \mathrm{Fe}_{0.1}\right)_{2}$ [11], (TiVZr) ${ }_{1}(\mathrm{CoFeMn})_{2}$ [27], and $\mathrm{Ti}_{1}\left(\mathrm{Cr}_{0.75} \mathrm{Mn}_{0.25}\right)_{2}$ [12]. Four alloys are within the range of values in which the highest incidence of formation of single C14 Laves phase compositions is observed. The alloy outside this range, $\operatorname{Ti}_{1}\left(\mathrm{Cr}_{0.75} \mathrm{Mn}_{0.25}\right)_{2}$, has $r_{A} / r_{B}$ and VEC values identical to the nonequiatomic $\mathrm{Ti}_{1}\left(\mathrm{Fe}_{0.15} \mathrm{Cr}_{0.85}\right)_{2}$ alloy (alloy number 73 ) predicted form single $\mathrm{C} 14$ Laves phase structure by CALPHAD. The amount of equilibrium phase as function of temperature calculated by CALPHAD for $(\mathrm{TiZr})_{1}(\mathrm{CrMnFeNi})_{2}$ and $\left(\mathrm{Ti}_{13} \mathrm{Zr}_{20}\right)_{1}\left(\mathrm{Nb}_{2.5} \mathrm{Fe}_{20} \mathrm{Ni}_{7.5} \mathrm{Ti}_{3.5}\right)_{2}$ were reported in literature $[9,10]$ and confirmed the prediction of single $\mathrm{C} 14$ phase structure (CALPHAD calculation of these two experimental compositions are also presented in Figure $\mathrm{S} 2$ of the supplementary material file). Figure 5 (c) shows the CALPHAD calculation for the $(\mathrm{Ti})_{1}\left(\mathrm{Cr}_{0.75} \mathrm{Mn}_{0.25}\right)_{2}$ alloy reported in [12], predicting crystallization as a major $\mathrm{C} 14$ Laves phase with a small fraction of a BCC phase being formed during the final stages of solidification. However, the fraction of C14 Laves phase increases as the temperature decreases, which could yield in a single C14 Laves phase depending on the processing route. The other two alloys were not calculated by CALPHAD because vanadium is not described in C14 Laves phase of the 
database used in this work. Therefore, V-containing alloy cannot be included in the present strategy to design single C14 Laves phase alloys.

However, from the proposed alloy design strategy it was possible to determine a range of VEC and $r_{A} / r_{B}$ values with the highest incidence of single C14 Laves phase alloys in which the $(\mathrm{TiZr})_{1}\left(\mathrm{~V}_{0.25} \mathrm{Ni}_{0.55} \mathrm{Mn}_{0.1} \mathrm{Fe}_{0.1}\right)_{2}$ [11] and $(\mathrm{TiVZr})_{1}(\mathrm{CoFeMn})_{2}$ [27] alloys fell inside. Therefore, these parameters can be an alternative tool to design V-containing single C14 Laves phase alloys while a database containing the description of $\mathrm{V}$ in the $\mathrm{C} 14$ Laves phase is not available.

The comparison between the experimental data with the thermodynamic calculations for the $(\mathrm{TiNb})_{1} \mathrm{Fe}_{2}, \quad(\mathrm{TiNb})_{1}(\mathrm{FeMnCr})_{2}, \quad(\mathrm{TiZr})_{1}(\mathrm{CrMnFeNi})_{2}$ [9], $\left(\mathrm{Ti}_{13} \mathrm{Zr}_{20}\right)_{1}\left(\mathrm{Nb}_{2.5} \mathrm{Fe}_{20} \mathrm{Ni}_{7.5} \mathrm{Ti}_{3.5}\right)_{2} \quad$ [10], and $\mathrm{Ti}_{1}\left(\mathrm{Cr}_{0.75} \mathrm{Mn}_{0.25}\right)_{2}$ [12] alloys demonstrated that the CALPHAD method with the database employed in this work are very powerful to predict the formation of single C14 Laves phase alloys. Figure $S 3$ of the supplementary data file shows the amount of equilibrium phase as function of temperature calculated by CALPHAD for all equiatomic (number 1 to 42 ) and non-equiatomic (number 43 to 142) alloys predicted to form single C14 Laves phase structures. Therefore, we were able to find 142 multicomponent alloys predicted to form single C14 Laves phase structure that will probably present different hydrogen storage properties. By assessing their hydrogen storage properties, different alloys from this pool can be selected for different applications.

\subsection{Prediction of hydrogen storage properties (calculation of PCT diagrams)}

To validate the thermodynamic model proposed in this work, a comparison between the calculated and experimental PCl curves for single C14 Laves phase alloys was carried out. The $\mathrm{PCl}$ at room temperature for the (TiNb) $\mathrm{Fe}_{2}$ $(\mathrm{TiNb})_{1}(\mathrm{FeMnCr})_{2}$ alloys were measured in this work, while PCT measurements for the $(\mathrm{TiZr})_{1}(\mathrm{CrMnFeNi})_{2} \quad[9], \quad\left(\mathrm{Ti}_{13} \mathrm{Zr}_{20}\right)_{1}\left(\mathrm{Nb}_{2.5} \mathrm{Fe}_{20} \mathrm{Ni}_{7.5} \mathrm{Ti}_{3.5}\right)_{2} \quad$ [10], $(\mathrm{TiZr})_{1}\left(\mathrm{~V}_{0.25} \mathrm{Ni}_{0.55} \mathrm{Mn}_{0.1} \mathrm{Fe}_{0.1}\right)_{2}$ [11], and $\mathrm{TiCr}_{1.5} \mathrm{Mn}_{0.5}$ [12] were reported in literature. Figure 7 shows the comparison between the calculated PCls using the thermodynamic model and the experimental PCls for the six alloys. Table 5 presents the calculated values of $h_{C 14}$ for the six tested alloys. The atomic 
fractions of $\mathrm{A}$ and $\mathrm{B}$ sites $\left(c_{i}^{A}\right.$ and $\left.c_{i}^{B}\right)$ for these alloys are presented in Table S2 of the supplementary data file (it is worth mentioning that these atomic fractions for the $\left(\mathrm{Ti}_{13} \mathrm{Zr}_{20}\right)_{1}\left(\mathrm{Nb}_{2.5} \mathrm{Fe}_{20} \mathrm{Ni}_{7.5} \mathrm{Ti}_{3.5}\right)_{2}$ alloy were calculated by CALPHAD and, in this case, some fraction of $\mathrm{Ti}$ and $\mathrm{Nb}$ occupy the $\mathrm{B}$ sites together with $\mathrm{Fe}$ and $\mathrm{Ni}$ whereas only $\mathrm{Ti}$ and $\mathrm{Zr}$ occupy the $\mathrm{A}$ site). One can see that the $(\mathrm{TiZr})_{1}\left(\mathrm{~V}_{0.25} \mathrm{Ni}_{0.55} \mathrm{Mn}_{0.1} \mathrm{Fe}_{0.1}\right)_{2}$ present the most negative value of $h_{C 14}(-25.8$ $\mathrm{kJ} / \mathrm{mol}$ of $\mathrm{H}$ ) amongst the tested alloys. There is a good agreement between the calculated and experimental $\mathrm{PCl}$ curves at $305 \mathrm{~K}$ for the $(\mathrm{TiZr})_{1}\left(\mathrm{~V}_{0.25} \mathrm{Ni}_{0.55} \mathrm{Mn}_{0.1} \mathrm{Fe}_{0.1}\right)_{2}$ alloy as can be seen in Figure 7. Moreover, the absence of a well-defined plateau pressure indicates that the hydrogen absorption in this alloy occurred only by interstitial solid solution as considered in the development of this model. The second lower value of $h_{C 14}$ was presented by the $\left(\mathrm{Ti}_{13} \mathrm{Zr}_{20}\right)_{1}\left(\mathrm{Nb}_{2.5} \mathrm{Fe}_{20} \mathrm{Ni}_{7.5} \mathrm{Ti}_{3.5}\right)_{2}$ alloy $(-20.0 \mathrm{~kJ} / \mathrm{mol}$ of $\mathrm{H})$ and again a good agreement between the calculated and experimental PCl curves at $305 \mathrm{~K}$ was observed. In this case, the calculated equilibrium pressures were only slightly higher than the experimental ones. The $\mathrm{Ti}_{1}\left(\mathrm{Cr}_{0.75} \mathrm{Mn}_{0.25}\right)_{2}$ and $(\mathrm{TiZr})_{1}(\mathrm{CrMnFeNi})_{2}$ alloys presented intermediate values of $h_{C 14},-15.4$ and $-17.5 \mathrm{~kJ} / \mathrm{mol}$ of $\mathrm{H}$, respectively. It is worth noting that the experimental PCls at $305 \mathrm{~K}$ for these alloys presented a flat plateau, which may suggest that a phase separation between a low hydrogen content solid solution and high hydrogen content hydride might occur for these alloys. This phase separation might be understood as a hydrogen miscibility gap in C14 Laves phase alloy and was not considered in the model proposed here. A miscibility gap means that there are two minimums in the $\Delta G_{m}\left(c_{H}\right)$ curve, which could result from a non-linear behavior of $\Delta H_{m}\left(c_{H}\right)$ or for occupancy of preferential interstitial sites associated with SBE, which could affect $\Delta S_{m}\left(c_{H}\right)$. Although intriguing and very interesting, the discussion of these effects is out of the scope of this work and deserves to be carefully investigated in the future. In spite of the shapes of the calculated PCl curves for the $\mathrm{Ti}_{1}\left(\mathrm{Cr}_{0.75} \mathrm{Mn}_{0.25}\right)_{2}$ and $(\mathrm{TiZr})_{1}(\mathrm{CrMnFeNi})_{2}$ alloys do not correspond to the experimental ones, the equilibrium pressure measured in the middle of the plateau pressure were well determined by the model. One can see that the calculated curves intersect the experimental PCls at around $c_{H}=0.5$, meaning a reasonable value of $h_{C 14}$ for these alloys. As predicted by our model, the equilibrium pressures of the 
$\mathrm{Ti}_{1}\left(\mathrm{Cr}_{0.75} \mathrm{Mn}_{0.25}\right)_{2}$ were approximately one order of magnitude higher than the $(\mathrm{TiZr})_{1}(\mathrm{CrMnFeNi})_{2}$ alloy. Finally, the alloys produced in this work, $(\mathrm{TiNb})_{1} \mathrm{Fe}_{2}$ and $(\mathrm{TiNb})_{1}(\mathrm{FeMnCr})_{2}$, presented the higher values of $h_{C 14},-7.25$ and $-11.7 \mathrm{~kJ} / \mathrm{mol}$ of $\mathrm{H}$, respectively. Such higher values predicted high equilibrium pressures for these alloys at room temperature (approximately $2 \times 10^{4}$ and $4 \times 10^{2}$ atm, respectively, for $c_{H}=0.5$ ), far above the high-pressure limit of our equipment ( 80 atm). Therefore, our calculations predicted that only a small amount of hydrogen would be absorbed by these alloys at room temperature in the pressure range available, which was indeed observed. One can see that the calculated and experimental curve for the $(\mathrm{TiNb})_{1} \mathrm{Fe}_{2}$ alloy in the measured range has a very good agreement. The experimental $\mathrm{PCl}$ curve of the $(\mathrm{TiNb})_{1}(\mathrm{FeMnCr})_{2}$ alloy presents equilibrium pressures slightly higher than the calculated ones, however, still in good agreement. The model predicted that the equilibrium pressures of the ( $\mathrm{TiNb})_{1} \mathrm{Fe}_{2}$ alloy would be higher than for the $(\mathrm{TiNb})_{1}(\mathrm{FeMnCr})_{2}$ and, consequently, that the maximum $\mathrm{H}$ uptake at 80 atm for the former alloy would be smaller than for the last one. Both predictions were true.

Table 5: Calculated $h_{C 14}$ in $\mathrm{kJ} / \mathrm{mol}$ of $\mathrm{H}$ calculated for the tested alloys.

\begin{tabular}{|c|c|}
\hline Alloy & $\boldsymbol{h}_{C 14}$ \\
\hline$(\mathrm{TiNb})_{1} \mathrm{Fe}_{2}$ & -7.25 \\
\hline$(\mathrm{TiNb})_{1}(\mathrm{FeMnCr})_{2}$ & -11.7 \\
\hline$(\mathrm{TiZr})_{1}(\mathrm{CrMnFeNi})_{2}$ & -17.5 \\
\hline$\left(\mathrm{Ti}_{13} \mathrm{Zr}_{20}\right)_{1}\left(\mathrm{Nb}_{2.5} \mathrm{Fe}_{20} \mathrm{Ni}_{7.5} \mathrm{Ti}_{3.5}\right)_{2}$ & -20.0 \\
\hline$\left(\mathrm{TiZr}_{1}{ }_{1}\left(\mathrm{~V}_{0.25} \mathrm{Ni}_{0.55} \mathrm{Mnn}_{0.1} \mathrm{Fe}_{0.1}\right)_{2}\right.$ & -25.8 \\
\hline $\mathrm{Ti}_{1}\left(\mathrm{Cr}_{0.75} \mathrm{Mnn}_{0.25}\right)_{2}$ & -15.4 \\
\hline
\end{tabular}




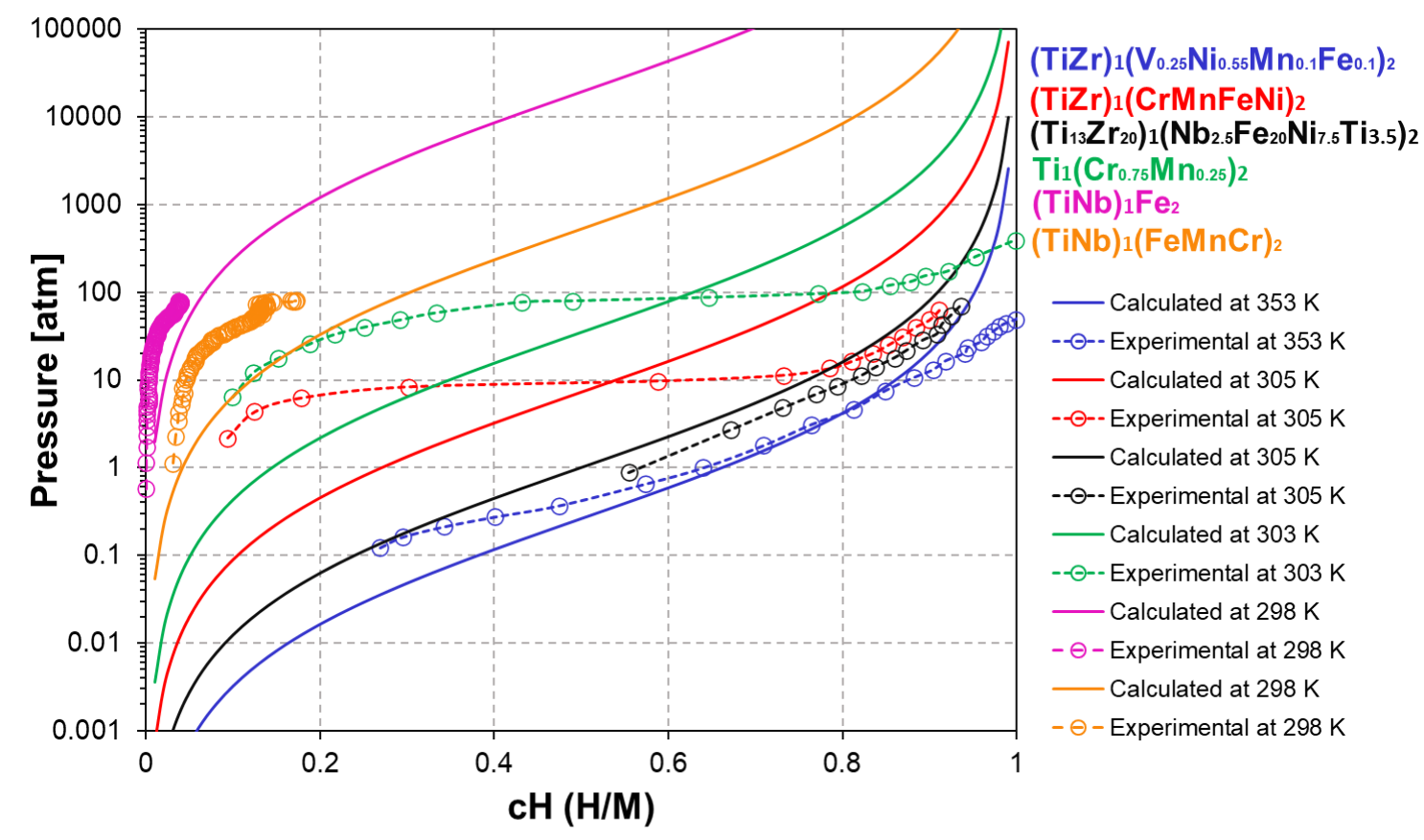

Figure 7: Experimental absorption $\mathrm{PCl}$ of the $(\mathrm{TiNb})_{1} \mathrm{Fe}_{2},(\mathrm{TiNb})_{1}(\mathrm{FeMnCr})_{2}$, $(\mathrm{TiZr})_{1}(\mathrm{CrMnFeNi})_{2}$ (experimental data taken from [9]), $\left(\mathrm{Ti}_{13} \mathrm{Zr}_{20}\right)_{1}\left(\mathrm{Nb}_{2.5} \mathrm{Fe}_{20} \mathrm{Ni}_{7.5} \mathrm{Ti}_{3.5}\right)_{2}$ (experimental data taken from [10]), (TiZr) ${ }_{1}\left(\mathrm{~V}_{0.25} \mathrm{Ni}_{0.55} \mathrm{Mn}_{0.1} \mathrm{Fe}_{0.1}\right)_{2}$ (experimental data taken from [11]), $\mathrm{Ti}_{1}\left(\mathrm{Cr}_{0.75} \mathrm{Mn}_{0.25}\right)_{2}$ (experimental data taken from [12]) alloys compared with the calculated PCls using the thermodynamic model proposed in this study.

The results presented in Figure 7 show that the six alloys used to validate the proposed model have equilibrium pressures at room temperature for the same $c_{H}$ varying within a six order of magnitude range. The model was very efficient to determine the order of magnitude of the equilibrium pressure for the $\mathrm{PCl}$ curves for the six alloys, yielding in a fair prediction of the trend of the alloys in terms of operation pressure and temperature. Therefore, despite its simplicity, the proposed model can be easily implemented in high throughput calculation to calculate $\mathrm{PCl}$ curves or PCT diagrams to determine the optimal operation pressure-temperature for an alloy. Once the predictability of the thermodynamic model to calculate the $\mathrm{PCl}$ curves was assessed, we can calculate the $\mathrm{PCl}$ curves at room temperature for the 142 alloys predicted to form single C14 Laves phase structures. For the calculation of the $\mathrm{PCl}$ curves (or PCT diagrams), it is necessary first to calculate $h_{C 14}$ for all the alloys. The $c_{i}^{A}$ and $c_{i}^{B}$ values for each 
one of the 142 alloys are shown in Table S3 of the supplementary data file. Table S3 also presents the resultant $h_{C 14}$ for each alloy.

Figure 8 shows the calculated $\mathrm{PCl}$ diagrams at room temperature for the 42 equiatomic compositions (alloys with very close or overlapping PCls were indicated by their respective alloy number). As can be seen in Figure 8(a), a wide range of hydrogen equilibrium pressure at room temperature was found. For the sake of clarity, we will always refer to the equilibrium pressure at $c_{H}=0.5$. The minimum hydrogen equilibrium pressure of $7.6 \times 10^{-3} \mathrm{~atm}$ was found for the $\mathrm{TiMn}_{2}$, $\mathrm{ZrMn}_{2}$, and ( $\left.\mathrm{TiZr}\right)_{1} \mathrm{Mn}_{2}$ compositions (alloys 2, 3, and 9, respectively). The maximum hydrogen equilibrium pressure of $5.9 \times 10^{5}$ atm was observed for the $\mathrm{NbFe}_{2}$ composition (alloy number 4 ).

To evaluate the influence of the molar mass in the gravimetric hydrogen absorption capacity of the alloys, Figure 8 (b) shows the same $\mathrm{PCl}$ curves in terms of hydrogen content in weight percent (wt.\%). There are three groups of alloys that show different tendencies during hydrogen absorption: alloys that absorb approximately up to $1.5 \mathrm{wt} . \%$ of hydrogen, alloys that absorb between $1.5 \mathrm{wt} . \%$ and $1.7 \mathrm{wt} . \%$ of hydrogen, and alloys that absorb more than $1.8 \mathrm{wt} . \%$ of hydrogen. The first group of alloys includes alloys, such as the alloys number 4 , $14,18,20$, and 30 , which have the highest weight ( $68.56 \mathrm{~g} / \mathrm{mol}$ on average). The second group of alloys includes alloys, such as the alloys number 7, 25, 34, 40, and 41. The molar weight of these compositions is lower in comparison with the first group ( $62.04 \mathrm{~g} / \mathrm{mol}$ on average). Finally, the third group of alloys includes the alloys number 1, 2, 11, 12, and 29. These compositions have the lowest molar weight $(52.90 \mathrm{~g} / \mathrm{mol}$ on average). The molar weight of all alloys is also shown in Table S2. 


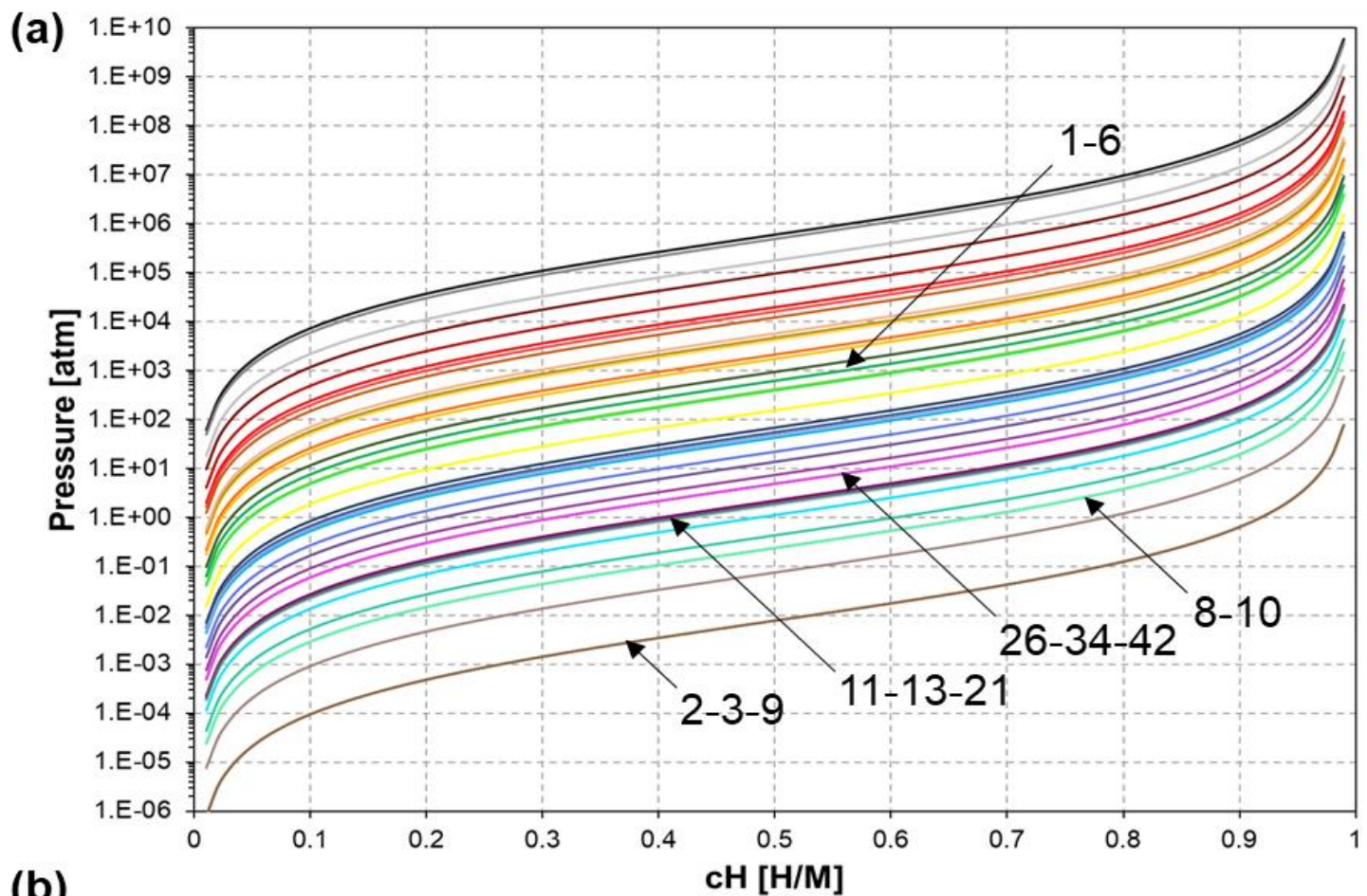

(b)

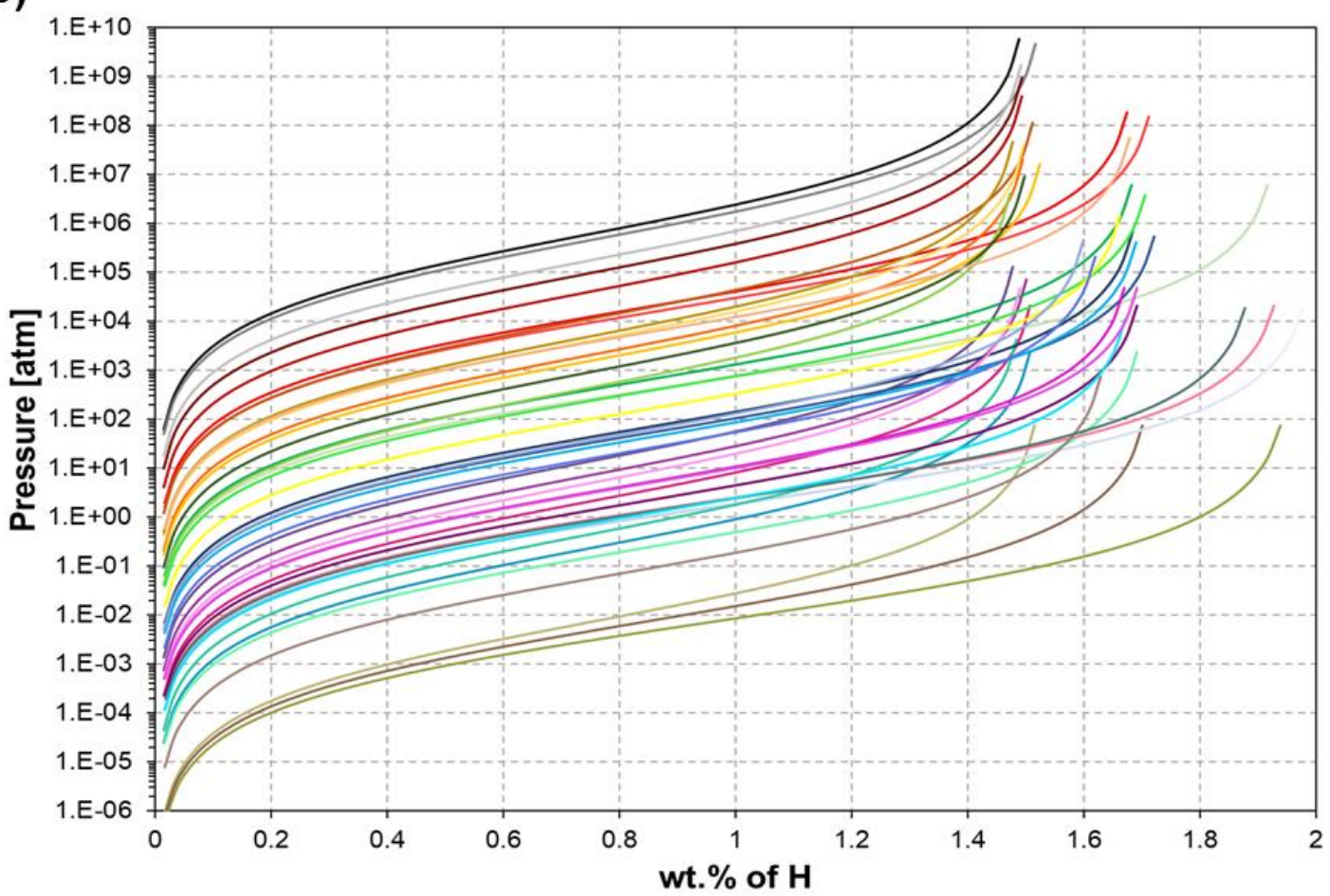

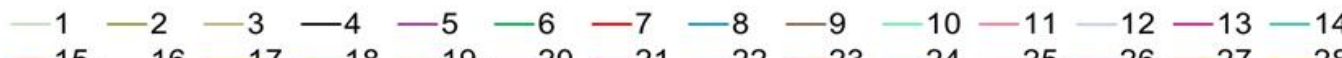

$$
\begin{aligned}
& -15-16-17-18-19-20-21-22-23-24-25-26-27-28 \\
& -29-30-31-32-33-34-35-36-37-38-39-40-41-42
\end{aligned}
$$

Figure 8: Calculated $\mathrm{PCl}$ diagrams at room temperature for equiatomic compositions (alloy number 1 to 42 ) using the thermodynamic model. The hydrogen equilibrium pressure in function of the hydrogen content in terms of (a) hydrogen-to-metal ratio $(\mathrm{H} / \mathrm{M})$ and (b) weight percent (wt.\%). 
Figure 9 shows the calculated $\mathrm{PCls}$ for the 100 non-equiatomic alloys (numbers from 43 to 142) divided into four graphs (25 compositions per graph in descending order of equilibrium pressures (to see the 100 compositions plotted together, see Figure S3 of the suplementary data file). Alloys with very close or overlapping PCls were indicated by their respective alloy number. Figures 9 (a) to (d) shows the hydrogen equilibrium pressure as a function of the hydrogen content in terms of $c_{H}$ and Figures $9(\mathrm{e})$ to $(\mathrm{h})$ in terms of \%wt. The hydrogen equilibrium pressure ranges from $10.0 \times 10^{-3} \mathrm{~atm}$ to $4.5 \times 10^{5} \mathrm{~atm}$, for the alloys number 91 and 121, respectively, and hydrogen storage capacity ranges from 1.4 to 2.0 for alloys 127 and 73 . 

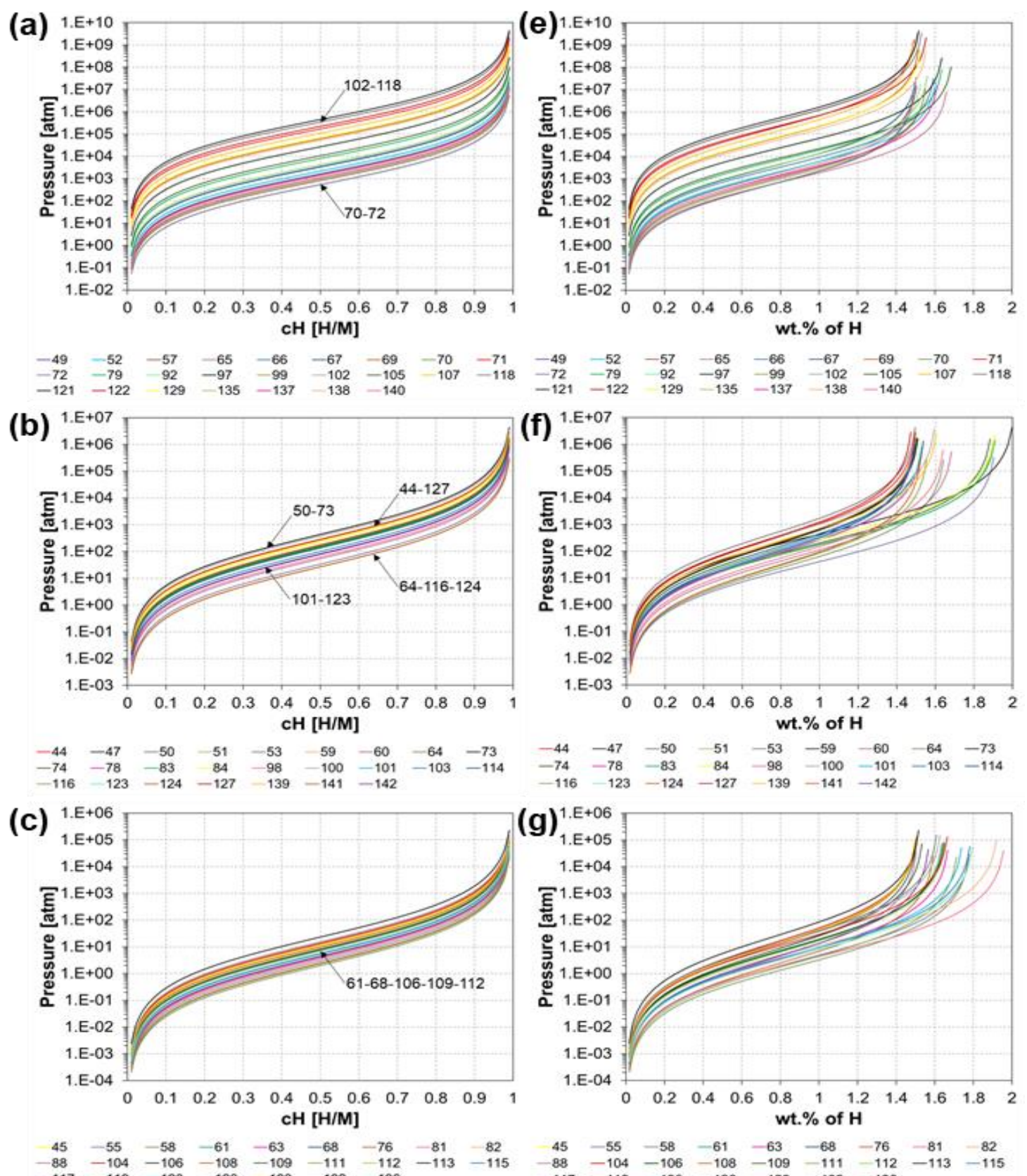

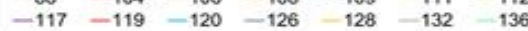
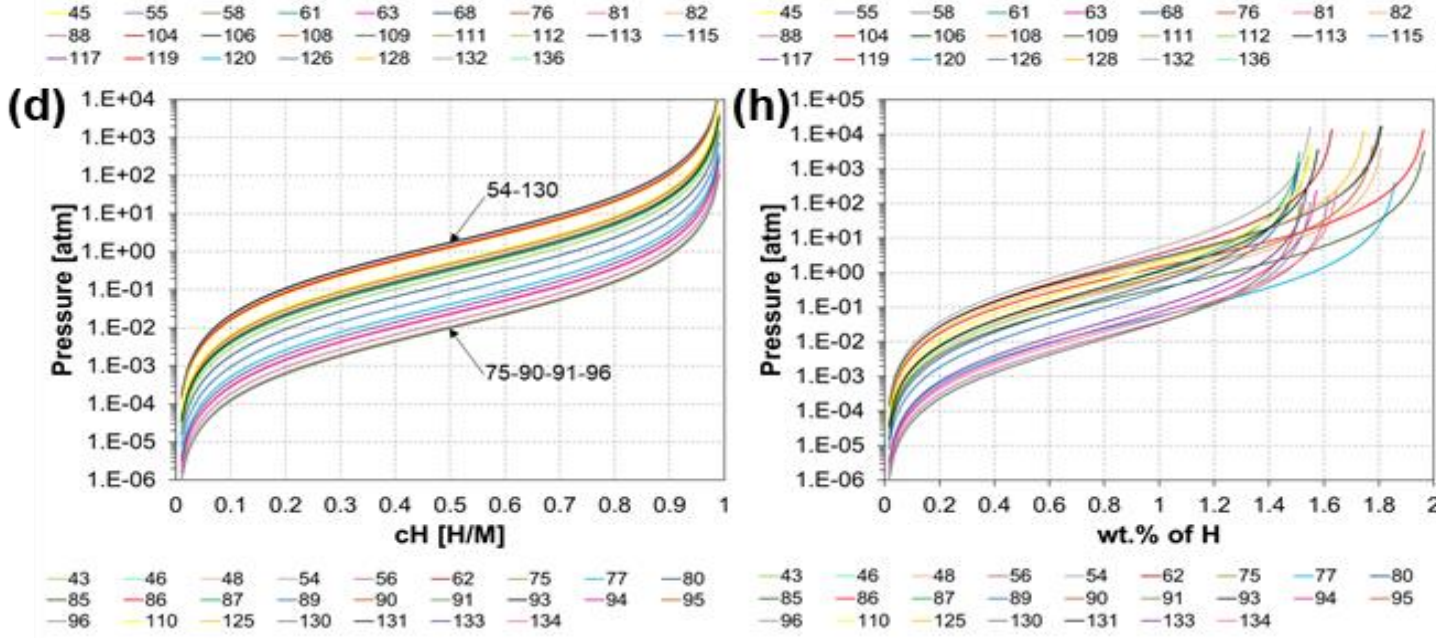

Figure 9: Calculated $\mathrm{PCl}$ diagrams at room temperature for non-equiatomic compositions (alloy number 43 to 142) using the thermodynamic model. The 
hydrogen equilibrium pressure in function of the hydrogen content in terms of (a), (b), (c), (d) hydrogen-to-metal ratio $(\mathrm{H} / \mathrm{M})$ and (e), (f), (g), (h) weight percent (wt.\%).

Figure 10 shows a chart of the equilibrium pressure (having $c_{H}=0.5$ ) versus the maximum theoretical hydrogen storage capacity in terms of weight percent considering $c_{H, \max }=1$ (these values are also shown in Table S3). This chart summarizes the thermodynamic hydrogen storage properties at room temperature for the 142 single C14 Laves phase alloys, showing that this class of alloys can have a wide range of hydrogen storage properties. This design strategy can be used to select alloy compositions with suitable properties for any specific hydrogen storage application. For instance, for room temperature hydrogen storage tank, alloys with high hydrogen storage capacity and equilibrium pressures varying between 2 and 20 atm (so they can absorb hydrogen at moderate pressures and desorb at room temperature in atmospheric pressure) are suitable. The alloys inside the green rectangles in Figure 10 are promising candidates for this application. Another promising application for hydrogen storage are the hybrid tanks that combine high pressure $\mathrm{H}_{2}$ (up to 700 atm) with high pressure MHs [28, 29]. For this application, alloys with equilibrium pressures at room temperature around 200 and 400 atm are needed, and high gravimetric capacity can help to reduce the weight systems; for this application the alloys within the blue rectangle in Figure 10 might be promising candidates. As a last example, for $\mathrm{Ni}-\mathrm{MH}$ batteries the gravimetric capacity of the hydride must be high to increase the charging capacity of the battery, however, the equilibrium pressure must be between 0.1 and 1 atm so the self-discharging is minimized and the pressure inside the battery does not reach pressure levels above the atmospheric [30]. The AB 5 -type alloys largely used nowadays have maximum hydrogen storage capacity of about $1.4 \mathrm{wt} . \%$, therefore, the alloys within the yellow rectangle in Figure 10 are potential candidates for Ni-MH battery application. Of course, other properties such as cycling stability in alkaline solution must be further evaluated. 


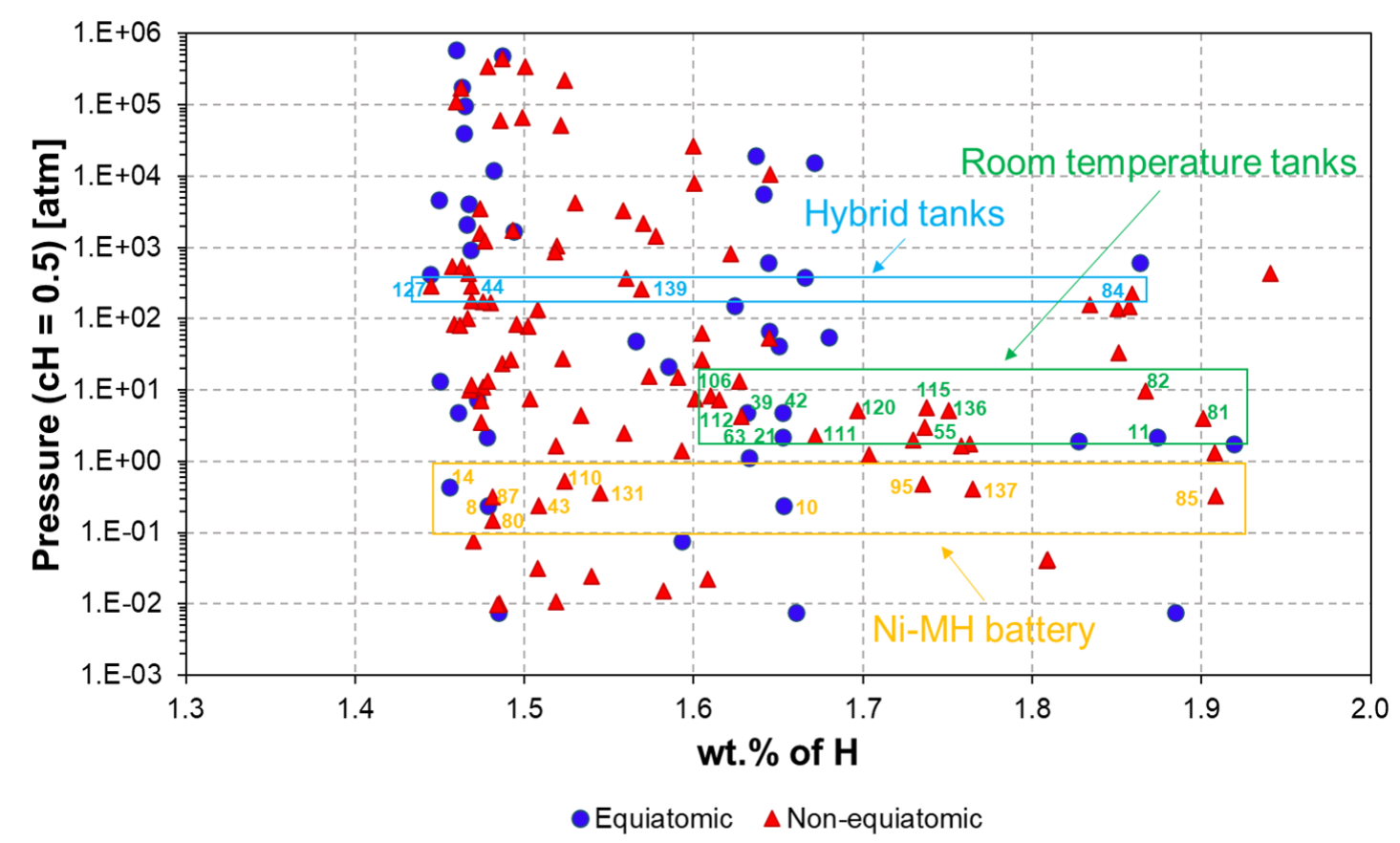

Figure 10: Chart of the hydrogen equilibrium pressure values (alloys having $c_{H}$ $=0.5)$ versus the maximum theoretical hydrogen content in weight percent considering $c_{H, \max }=1$.

\section{Conclusions}

In this work, a strategy to design single C14 Laves phase multicomponent alloys for hydrogen storage assisted by computational thermodynamic was presented. First, combining high-throughput calculations of VEC, $r_{A} / r_{B}$, and $\delta$ with CALPHAD method allowed us to find 142 multicomponent alloys predicted to form single $\mathrm{C} 14$ Laves phase. In addition, a thermodynamic model to calculate PCT diagrams for C14 Laves phase alloys was presented. The model was first applied to six experimental C14 Laves phase alloys, and the calculated PCls were compared with the experimental ones. The good agreement between the calculated and experimental data verified that this model can be applied for calculating reasonably accurate PCTs contributing to alloy's design. Applying the model to calculate the PCT diagrams to the 142 alloys predicted to form single C14 Laves phase, it was shown that is possible to produce single C14 Laves phase alloys with a wide range of hydrogen storage properties. Therefore, the strategy presented here allows the design of many alloys with suitable properties for different hydrogen storage applications. 


\section{Acknowledgements}

This work was financed in part by the Serrapilheira Institute (grant number Serra-1709-17362) and in part by Sao Paulo State Research Support Foundation (project number: 2021/00912-6). This study was also financed in part by the Coordenação de Aperfeiçoamento de Pessoal de Nível Superior - Brasil (CAPES) - Finance Code 001, Federal University of Sao Carlos, Graduate Program in Materials Science and Engineering.

\section{References}

[1] Møller, K.T., Jensen, T.R., Akiba, E., Li, H. Wen, Hydrogen - A sustainable energy carrier. Prog. Nat. Sci. Mater. Int. 27 (2017) 34-40. doi:10.1016/j.pnsc.2016.12.014

[2] Hirscher, M., Yartys, V.A., Baricco, M., Bellosta von Colbe, J., Blanchard, D., Bowman, R.C., Broom, D.P., Buckley, C.E., Chang, F., Chen, P., Cho, Y.W., Crivello, J.C., Cuevas, F., David, W.I.F., de Jongh, P.E., Denys, R. V., Dornheim, M., Felderhoff, M., Filinchuk, Y., Froudakis, G.E., Grant, D.M., Gray, E.M.A., Hauback, B.C., He, T., Humphries, T.D., Jensen, T.R., Kim, S., Kojima, Y., Latroche, M., Li, H.W., Lototskyy, M. V., Makepeace, J.W., Møller, K.T., Naheed, L., Ngene, P., Noréus, D., Nygård, M.M., Orimo, S. ichi, Paskevicius, M., Pasquini, L., Ravnsbæk, D.B., Veronica Sofianos, M., Udovic, T.J., Vegge, T., Walker, G.S., Webb, C.J., Weidenthaler, C., Zlotea, C.: Materials for hydrogen-based energy storage - past, recent progress and future outlook. J. Alloys Compd. 827, (2020). doi:10.1016/j.jallcom.2019.153548

[3] Schlapbach, L., Züttel, A., Hydrogen-storage materials for mobile applications. Nature. 414 (2001) 353-358. doi:10.1038/35104634

[4] Marinelli, M., Santarelli, M., Hydrogen storage alloys for stationary applications. J. Energy Storage. 32, 101864 (2020). doi:10.1016/j.est.2020.101864

[5] Miracle, D.B., Senkov, O.N., A critical review of high entropy alloys and related concepts. Acta Mater. 122 (2017) 448-511. doi:10.1016/j.actamat.2016.08.081

[6] Marques, F., Balcerzak, M., Winkelmann, F., Zepon, G., Felderhoff, M., 
Review and outlook on high-entropy alloys for hydrogen storage. Energy Environ. Sci. (2021). doi:10.1039/d1ee01543e

[7] Stein, F., Leineweber, A., Laves phases: a review of their functional and structural applications and an improved fundamental understanding of stability and properties. J. Mater. Sci. 56 (2021) 5321-5427. doi:10.1007/s10853-020-05509-2

[8] Kohlmann, H., Hydrogen order in hydrides of Laves phases. Zeitschrift fur Krist. - Cryst. Mater. 235 (2020) 319-332. doi:10.1515/zkri-2020-0043

[9] Edalati, P., Floriano, R., Mohammadi, A., Li, Y., Zepon, G., Li, H.W., Edalati, K., Reversible room temperature hydrogen storage in high-entropy alloy TiZrCrMnFeNi. Scr. Mater. $178 \quad$ (2020) 387-390. doi:10.1016/j.scriptamat.2019.12.009

[10] Floriano, R., Zepon, G., Edalati, K., Fontana, G.L.B.G., Mohammadi, A., $\mathrm{Ma}, \mathrm{Z}$., Li, H.W., Contieri, R.J., Hydrogen storage in TiZrNbFeNi high entropy alloys, designed by thermodynamic calculations. Int. J. Hydrogen Energy. 45 (2020) 33759-33770. doi:10.1016/j.jjhydene.2020.09.047

[11] Akiba, E., Iba, H., Hydrogen absorption by Laves phase related BCC solid solution. Intermetallics. 6 (1998) 461-470. doi:10.1016/S09669795(97)00088-5

[12] Charbonnier, V., Enoki, H., Asano, K., Kim, H., Sakaki, K., Tuning the hydrogenation properties of Ti1+Cr2-Mn laves phase compounds for high pressure metal-hydride compressors. Int. J. Hydrogen Energy. 1-12 (2021). doi:10.1016/j.jijhydene.2021.08.143

[13] Chen, S.K., Lee, P.H., Lee, H., Su, H.T., Hydrogen storage of C14CruFevMnwTixVyZrz alloys. Mater. Chem. Phys. 210 (2018) 336-347. doi:10.1016/j.matchemphys.2017.08.008

[14] Gesari, S.B., Pronsato, M.E., Visintin, A., Juan, A., Hydrogen storage in AB2 Laves phase $(A=\mathrm{Zr}, \mathrm{Ti} ; \mathrm{B}=\mathrm{Ni}, \mathrm{Mn}, \mathrm{Cr}, \mathrm{V})$ : Binding energy and electronic structure. J. Phys. Chem. C. 114 (2010) 16832-16836. doi:10.1021/jp106036v

[15] Gorban', V.F., Krapivka, N.A., Firstov, S.A., High-entropy alloys: Interrelations between electron concentration, phase composition, lattice parameter, and properties. Phys. Met. Metallogr. 118 (2017) 970-981. doi:10.1134/S0031918X17080051 
[16] Yurchenko, N., Stepanov, N., Salishchev, G., Laves-phase formation criterion for high-entropy alloys. Mater. Sci. Technol. 33 (2017) 17-22. doi:10.1080/02670836.2016.1153277

[17] Mishra, S.S., Yadav, T.P., Srivastava, O.N., Mukhopadhyay, N.K., Biswas, K., Formation and stability of $\mathrm{C} 14$ type Laves phase in multi component high-entropy alloys. J. Alloys Compd. 832 (2020) 153764. doi:10.1016/j.jallcom.2020.153764

[18] Xian, Y., Zheng, H., Zhai, Q., Luo, Z., A two-dimensional structure map for prediction of the transition-metal Laves phases. Comput. Mater. Sci. 125 (2016) 1-7. doi:10.1016/j.commatsci.2016.08.023

[19] Zepon, G., Silva, B.H., Zlotea, C., Botta, W.J., Champion, Y., Thermodynamic modelling of hydrogen-multicomponent alloy systems: Calculating pressure-composition-temperature diagrams. Acta Mater. 215 (2021) 117070. doi:10.1016/j.actamat.2021.117070

[20] Guo, S., Liu, C.T., Phase stability in high entropy alloys: Formation of solidsolution phase or amorphous phase. Prog. Nat. Sci. Mater. Int. 21 (2011) 433-446. doi:10.1016/S1002-0071(12)60080-X

[21] Griessen, R., Riesterer, T., Heat of formation models. (1988) 219-284. doi:10.1007/3540183337_13

[22] Flanagan, T.B., Oates, W.A., Some thermodynamic aspects of metal hydrogen systems. J. Alloys Compd. 404-406 (2005) 16-23. doi:10.1016/j.jallcom.2004.11.108

[23] Flanagan, T.B., Oates, W.A., Thermodynamics of intermetallic CompoundHydrogen Systems, in: 1988: pp. 49-85. doi:10.1007/3540183337_10.

[24] Merlino, A.R., Luna, C.R., Juan, A., Pronsato, M.E., ScienceDirect Laves phase. Int. J. Hydrogen Energy. (2015) 1-11. doi:10.1016/j.ijhydene.2015.10.077

[25] Fukai, Y. The Metal-Hydrogen System; Springer: Berlin/Heidelberg, Germany, 2005. doi:10.1007/3-540-28883-X.

[26] Garcés, J. The configurational entropy of mixing of interstitials solid solutions. Appl. Phys. Lett. 96 (2010) 67-70. doi:10.1063/1.3400221

[27] Sarac, B., Zadorozhnyy, V., Berdonosova, E., Ivanov, Y.P., Klyamkin, S., Gumrukcu, S., Sarac, A.S., Korol, A., Semenov, D., Zadorozhnyy, M., Sharma, A., Greer, A.L., Eckert, J., Hydrogen storage performance of the 
multi-principal-component CoFeMnTiVZr alloy in electrochemical and gas$\begin{array}{llllll}\text { solid reactions. RSC Adv. } 10 & \text { (2020) 24613-24623. }\end{array}$ doi:10.1039/d0ra04089d

[28] Weidenthaler, C., Felderhoff, M., Solid-state hydrogen storage for mobile applications: Quo Vadis? Energy Environ. Sci. 4 (2011) 2495-2502. doi:10.1039/c0ee00771d

[29] Felderhoff, M., Weidenthaler, C., Von Helmolt, R., Eberle, U., Hydrogen storage: The remaining scientific and technological challenges. Phys. Chem. Chem. Phys. 9 (2007) 2643-2653. doi:10.1039/b701563c

[30] Notten, P.H.L. Rechargeable nickel-metalhydride batteries: a successful new concept. Interstitial Intermet. Alloy. (1995) 151-195. doi:10.1007/97894-011-0295-7_7 